\title{
Mechanism governing nanoparticle flow behaviour in porous media: insight for enhanced oil recovery applications
}

\author{
Augustine Agi $^{1}$ [D $\cdot$ Radzuan Junin $^{1} \cdot$ Afeez Gbadamosi $^{1}$
}

Received: 4 October 2017 / Accepted: 19 May 2018 / Published online: 4 June 2018

(c) The Author(s) 2018

\begin{abstract}
Nanotechnology has found its way to petroleum engineering, it is well-accepted path in the oil and gas industry to recover more oil trapped in the reservoir. But the addition of nanoparticles to a liquid can result in the simplest flow becoming complex. To understand the working mechanism, there is a need to study the flow behaviour of these particles. This review highlights the mechanism affecting the flow of nanoparticles in porous media as it relates to enhanced oil recovery. The discussion focuses on chemical-enhanced oil recovery, a review on laboratory experiment on wettability alteration, effect of interfacial tension and the stability of emulsion and foam is discussed. The flow behaviour of nanoparticles in porous media was discussed laying emphasis on the physical aspect of the flow, the microscopic rheological behaviour and the adsorption of the nanoparticles. It was observed that nanofluids exhibit Newtonian behaviour at low shear rate and non-Newtonian behaviour at high shear rate. Gravitational and capillary forces are responsible for the shift in wettability from oil-wet to water-wet. The dominant mechanisms of foam flow process were lamellae division and bubble to multiple bubble lamellae division. In a water-wet system, the dominant mechanism of flow process and residual oil mobilization are lamellae division and emulsification, respectively. Whereas in an oil-wet system, the generation of pre-spinning continuous gas foam was the dominant mechanism. The literature review on oil displacement test and field trials indicates that nanoparticles can recover additional oil. The challenges encountered have opened new frontier for research and are highlighted herein.
\end{abstract}

Keywords Nanoparticles $\cdot$ Porous media $\cdot$ Adsorption $\cdot$ Stability $\cdot$ Mechanisms $\cdot$ Enhanced oil recovery

\section{Introduction}

As most of the oil fields in the world are approaching maturation, more emphasis is placed on enhanced oil recovery (EOR) methods, because two thirds of the original oil in place (OOIP) is left unproduced. Since the porosity and permeability of most reservoirs varies, early breakthrough result in by-passed crude. EOR process can improve the recovery efficiency; chemical-enhanced oil recovery (CEOR) can recover about $37 \%$ OOIP. Oil can be trapped microscopically in the reservoir by capillary forces and oil can also be by passed macroscopically by water flood. CEOR therefore, is aimed at finding chemical that could be added to water to reduce the capillary forces and increase the sweep efficiency.

Radzuan Junin

r-radzuan@utm.my

1 Department of Petroleum Engineering, Faculty of Chemical and Energy Engineering, Universiti Teknologi Malaysia, UTM Skudai, 81310 Johor Bahru, Malaysia
The major chemical used in the industry to achieve this are polymer, surfactant and alkaline. Surfactant lowers the interfacial tension between the oil and water, alter the wettability of the rock, generate emulsion and stabilize foam. Polymers on the other hand increases the viscosity, which reduces the mobility ratio, and therefore improves the sweep efficiency, whereas alkali increase $\mathrm{pH}$, generate in situ surfactants and reduce adsorption of anionic surfactants [1]. The combination of all the chemicals alkaline, surfactant and polymer (ASP) is also in use but due to high cost of chemicals and fall in crude oil price, petroleum engineers has sought for ways to remedy this situation. With the introduction of nanotechnology in EOR, it is a way to solve the numerous problem plaguing the oil and gas industry.

Nanotechnology is the use of nanoparticles ranging from 1 to $100 \mathrm{~nm}$ size in the study of combination science, medical, engineering and technology. At present, nanotechnology has been used in medicine, electronics, electrical, space, science and engineering [2]. It has enjoyed wide range of use because of its large surface area which makes it easier to 
interact with solvent molecules when added to make suspension, optical transparency (copper nanoparticle), electrical conductivity (silicon nanoparticle), chemical catalyst (platinum nanoparticle), colour change (gold nanoparticle), thermal properties like heat transfer, cooling, insulation, and property of mechanical strength like ultra-high strength of material $[3,4]$.

Nanotechnology has also found its way to petroleum engineering, it is a well-accepted path in the oil and gas industry to recover more oil trapped in the reservoir, it has recorded success in reservoir characterization, drilling and well-completion jobs [5]. In EOR, nanoparticle is still in the laboratory stage where its efficiency is being studied. And few field trials have been reported [6]. Different laboratory studies $[7,8]$ and pilot field application have reported [6] that nanofluids can recover oil trapped in the reservoir. Therefore, nanoparticle can change the wettability of the rock surface, reduce interfacial tension between oil and water interface, and lower the chemical adsorption into the reservoir rock surface [9].

The application of nanoparticles in EOR process can be summarized into three major approaches; nanofluids, nanocatalyst and nanoemulsion [10]. Nanofluids are usually base fluid with nanoparticles size less than $100 \mathrm{~nm}$ in colloidal suspension [11]. The base fluid in this case can be water, oil or gas. Nanofluid in EOR are usually used to improve water flooding and the mechanism responsible include; IFT reduction, disjoining pressure, wettability reduction, viscosity increase, pore channel plugging and asphaltene precipitation. Nanoparticles can also be used to stabilize emulsion, it can overcome the challenges encountered by other stabilizers such as surfactants [12]. The high viscosity of nanoemulsion can control mobility ratio during flooding. It is therefore, very useful in heavy oil recovery [13]. And can penetrate through pore throats without much retention. Whereas nanocatalyst are used as catalyst in steam injection of heavy oil reservoir [14]. The advantages of using nanocatalyst to conventional catalyst include; upgrading of heavy oil reservoir by converting bitumen to lighter products. Nanocatalyst such as iron and nickel can also breakdown carbon-sulphur bonds within asphaltenes, increase saturates and aromatics in the heavy oil [10]. The summary of the application of nanoparticles in EOR is shown in Fig. 1.

Two characteristics of nanoparticles that make them very attractive to the oil and gas industry are their large surface area and the ability to manipulate their behaviour and structure. Therefore, nanotechnology involves the tailoring of a material at the atomic level to attain a unique property, which can then be manipulated at will for a certain application. The different types of nanoparticles are; metal nanoparticles (gold, silver, lead and iron), organic polymer nanoparticles and the inorganic polymer nanoparticles (silica, tin, germanium phosphorus and sulfur), the organic polymers can be natural or synthetic. The natural polymer

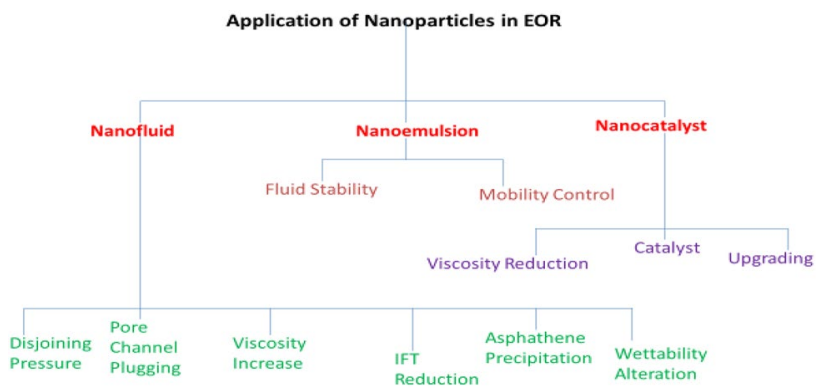

Fig. 1 Caption application of nanoparticles in EOR

nanoparticles include; sucrose, maltose, carbohydrate, chitosan, Arabic gum and biomolecules while the synthetic is mostly derived from petroleum products [4].

The addition of nanoparticles to a liquid, can result in the simplest flow becoming complex, to understand the working mechanism, there is need to study the flow behaviour of these particles. There are a lot of reviews on nanoparticles in oil and gas industry from Kong and Ohadi [15] to Sun et al. [10]. The work of Hadi et al. [16] was on polymer-coated nanoparticles, and Sharma et al. [17] discussed a little on the effect of surfactant on nanoparticles, but they are more general in the discussion, making the work of on this subject to be scattered in the literature.

This review, therefore, highlights the mechanism affecting the flow of nanoparticles in porous media as it relates to EOR. The discussion focuses on CEOR, a critical review on laboratory experiment on wettability alteration, effect of interfacial tension and the stability of emulsion and foam is discussed. The mechanisms affecting the flow behaviour of nanoparticles in porous media was discussed laying emphasis on the physical aspect of the flow, the microscopic rheological behaviour and the adsorption of the nanoparticle. A compilation of the experimental studies on nanoparticles flooding process as it affects incremental oil recovery is presented and two field trials are included. This review will provide update on existing literature on this subject and the recent development in CEOR. The challenges encountered have opened new frontier for research and are all highlighted herein.

\section{Nanotechnology in CEOR}

\section{Wettability alteration}

Wettability can be defined as the relationship between the solid surface to the solid-fluid and fluid-fluid interaction [18]. Spreading of liquids and wetting of surface influences oil recovery mechanism. Surface agents can change the wettability of rock surface; wettability affects capillary pressure and relative permeability curve. Nanoparticles have been proven to have great impacts on wettability alteration. The 
use of nanoparticles can form a two-dimensional layer in the presence of a three-phase contact region formed between the oily soil and the solid substrate [19]. It plays an important role in disjoining the structural pressure (force normal to the interface). The wettability of any solid surface can be determined using spontaneous imbibition, contact angle measurement, zeta potential measurement and surface imaging test.

The changing of the wettability of the reservoir rock from oil-wet to water-wet can ease extraction of oil and improve oil recovery [9]. A surface is said to be water-wet if the water contact angle is $<90^{\circ}$ and oil-wet if the water contact angle is $>90^{\circ} \mathrm{IFT}$.

\section{Mechanism of wettability alteration by nanoparticles}

The surface and interfacial energies are used to determine if a surface is water or oil wet, the contact angle formed is as a result of the force balance between the spreading coefficient $(S)$ of water on a solid in contact with both oil and water. Nanoparticles increase $S$ by removing the oily soils from solid surface using the mechanism called 'Rollup'. In laboratory experimentation, the contact angle, the Amott test, the centrifuge method, the core displacement test is used to determine wettability. The contact angle is used to determine the wettability of a three-phase system, it is used to determine formation wettability. The imaging method gives a clear picture of the wetting mechanism in oil-water-rock system as shown in Fig. 2. The centrifuge method uses the correlation between the degree of wetting and the area under the capillary pressure curve, it is consistent with the Amott method but better in near neutral area.

Wettability alteration by nanoparticles is due to their adsorption on the rock surface, which forms a water-wet layer on it. Adsorption of a very active and energetic material on a solid surface can significantly alter the surface energy and wettability of the system [20]. Adsorption happens when the balance between the capillary force and viscous forces changes. The viscous force is decreased, whereas the capillary force increases. Therefore, the viscous force needed to overcome capillary forces are reduced [21]. The large surface area of nanoparticles can lead to an increase in the proportion of atoms on the surface of the particles, which results in an increase in surface energy with the ability to alter the wettability of the rock [22]. Mohammed and Babadagli [23] described wettability alteration from oilwet to mix-wet and then to strongly water-wet condition by analysing the balance between capillary and gravitational forces. The shift in wettability from strong oil-wet to waterwet is because of two mechanisms. Firstly, from strong oil-wet to mix-wet and secondly from mixed-wet to strong water-wet [24]. The main factor in the first mechanism is gravitational forces, which change the balance of the wetting forces. And displaces the weight of the fluid from the bulk to the interface. Defined as capillary forces, by reducing the capillary forces, which leads to wettability alteration from strong oil-wet to mixed-wet [24]. Also, the component for
Fig. 2 Contact angle on a rock, a oil-air-rock before treatment, b oil-air-rock after treatment with silica, $\mathbf{c}$ water-air-rock before treatment, $\mathbf{d}$ water-airrock after treatment with silica nanoparticles [28]

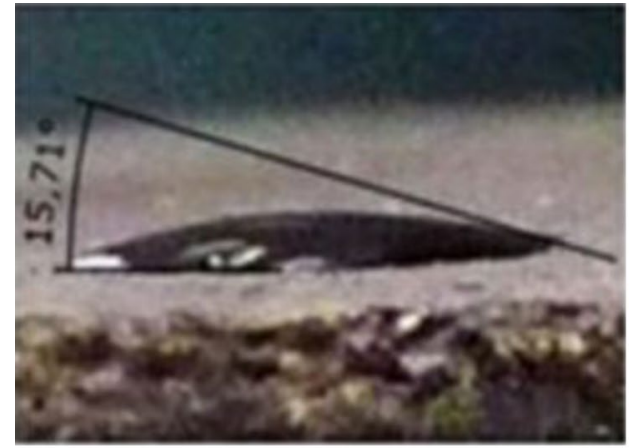

(a)

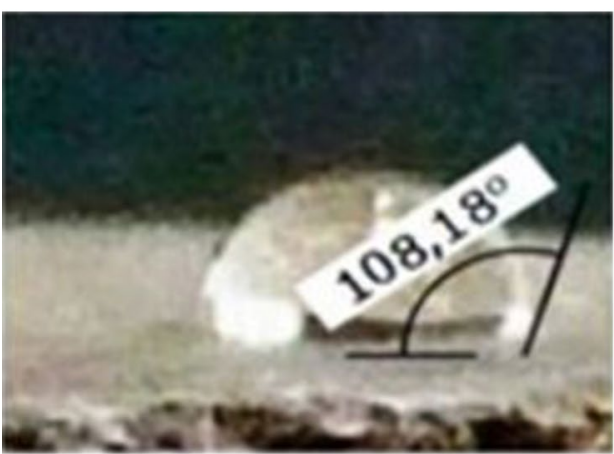

(c)

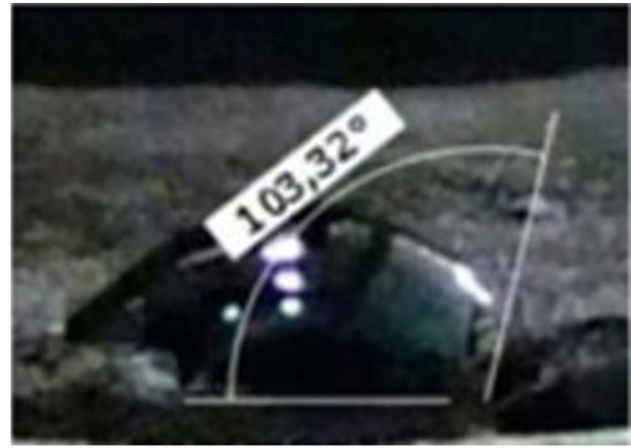

(b)

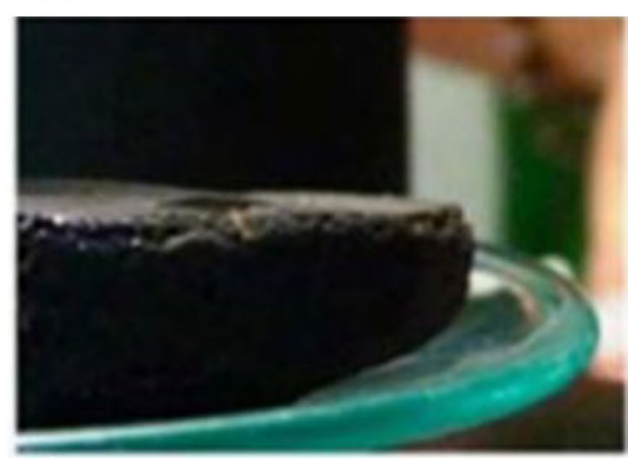

(d) 
oil/brine/rock such as oil/brine component, mineral surface, and system history condition may also control the wetting tendency [25].

Giraldo [20] observed that in a fluid containing nanoparticles or micelles immersed in oil droplet on a surface, they were two contact lines instead of one that is usually observed in a traditional mechanism. This inner and outer spreading lines, therefore, account for faster spreading of a nanoparticle solution on a surface for higher concentration and viscosity compared to traditional mechanism. Which might have led to increase in relative permeability of oil due to the wettability alteration by nanoparticles. Oil recovery can increase by $20 \%$ when high concentration of nanoparticles is injected. They suggested 2-3\% concentration as increase in concentration can result to decrease in permeability [26]. This is usually associated with the nanoparticle size, salt concentration and bulk volume [27, 28].

Moustafa et al. [29] used a combination of Magnesium/ Aluminium layered double hydroxide, their results show that $4.0 \mathrm{~g} \mathrm{~L}^{-1}$ concentration decreases the brine phase contact angle in the presence of oil from $66^{\circ}$ to $60^{\circ}$. Hendraningrat and Torsaeter [30] using Aluminium, Silicium and Titanium oxide nanoparticles on Berea sandstone core, reported a 5-7\% increase in recovery by Titanium oxide, this shows that the wettability was altered as Titanium made the quartz plate more water-wet. They concluded that oil recovery increases as nanoparticles size decreases and the contact angle alteration decreases towards more water-wet quartz. Karimi et al. [31] demonstrated that zircon oxide nanoparticles can alter the wettability of carbonate rock reservoir, the SEM and XRD analysis verified that nanoparticles can significantly change the wettability of reservoir rock. The influence of nanoparticles on wetting behaviour of fractured limestone was also demonstrated by Nwidee et al. [32]. They investigated the influence of zirconium(iv) oxide $\left(\mathrm{ZrO}_{2}\right)$ and nickel(ii) oxide (NiO). The contact angle measurement demonstrated that application of nanofluid in oil-wet or intermediate-wet formation can increase oil recovery by wettability alteration as the nanoparticles adsorb on the surface of the calcite crystals and promote oil displacement. Time, concentration and salinity where responsible for the decrease in the water contact angle. The work of Mohammadi et al. [21] shows the success of gamma alumina nanoparticles in enhancing oil recovery in carbonate rock when they observed a maximum change in contact angle and $11.25 \%$ increase in recovery. Ju and Fan [33] used lipophobic and hydrophobic polysilicon nanoparticles to alter the wettability of sandstone from oil-wet to water-wet. TEM analysis revealed that nanoparticles where attached to the pore walls. Again, the work of Li and Torsaeter [34] was an improved study on wettability alteration and they confirmed earlier reports. Ju et al. [26] using a physical model, mathematical model, and a numerical simulator were able to increase recovery by $15.38 \%$ when treated with waterwetting wettability control agent (IWWCA) and increasing the oil-wetting wettability control agent (IOWCA) improves recovery $(60-80 \%)$ in water injection rate. Onyekonwu and Ogolo [7] studied the wettability alteration of three different polysilicon nanoparticles to enhance oil recovery. The nanoparticles used were lipophobic and hydrophobic (LHPN), hydrophobic and lipophobic (HLPN) and neutrally wet (NWPN). They reported that HLPN and NWPN are good agent for enhanced oil recovery with a total recovery between 42.95 and $53.38 \%$ for LHPN, $70.62-86.92 \%$ for NWPN and $70.0-93.13 \%$ for HLPN.

Wan Sulaiman et al. [35] used silica nanoparticle in carbonate rock to alter the wettability of the rock, and to test the efficiency of silica nanoparticle in enhancing oil recovery in high salinity. They reported a $65.5 \%$ recovery of the original oil in place. Nazari et al. [36] in their work on wettability alteration of carbonate rocks, $\mathrm{ZrO}_{2}$, titanium dioxide $\left(\mathrm{TiO}_{2}\right)$, magnesium oxide $(\mathrm{MgO})$, aluminium dioxide $\left(\mathrm{Al}_{2} \mathrm{O}_{3}\right)$, cerium oxide $\left(\mathrm{CeO}_{2}\right)$ and carbon nanotube $(\mathrm{CNT})$, where all used for contact angle measurement while calcium carbonate $\left(\mathrm{CaCO}_{3}\right)$ and silicon dioxide $\left(\mathrm{SiO}_{2}\right)$ where used for core flooding. The result showed $8-9 \%$ additional recovery. Maghzi et al. [37] monitored the wettability alteration using silica nanoparticles during water flooding of heavy oil, they experimented with micromodel and reported a $26 \%$ incremental oil recovery using silica nanoparticles. Experimental results by some researcher are summarised in Table 1.

\section{Challenges of nanoparticles in altering wettability}

Some factors could mitigate against the success of wettability alteration using nanoparticles, such factors include; concentration of the nanoparticles, nature of the reservoir, hydrophobicity of the nanoparticles, type of nanoparticles and nature of the oil.

Hydrophilic polysilicon makes a water-wet formation more water-wet, and this might lead to poor recovery [7, 38]. Therefore, hydrophilic polysilicon nanoparticles should be restricted to oil-wet formation while, the hydrophobic polysilicon should be restricted to water-wet formation. The nature of the oil also has a significant role to play in wettability alteration, the selection of nanoparticles should depend on the type of oil. Roustaei et al. [39] reported that silicon oxide is more effective in the wettability alteration of light oil. Whereas Huibers et al. [40] recommend the use of silica nanoparticles when the contact angle in light crude was mostly affected by the addition of $0.001 \mathrm{wt} \%$ nanoparticle, which altered the wettability of sandstone. While the contact angle of light crude plateaux, the heavy oil continued to increase with increase in nanoparticle concentration, indicating that a maximum contact angle in heavy oil was not achieved. Nanoparticles disrupts the viscoelastic network 
Table 1 Summary of the effects of nanoparticles in enhanced oil recovery

\begin{tabular}{|c|c|c|c|c|}
\hline References & Nanoparticle used & Recovery $(\%)$ & Porous MEDIA & Behaviour/finding \\
\hline Ju et al. [26] & Polysilicon & 20 & & $\begin{array}{l}\text { Due to wettability alteration, recovery } \\
\text { increased by } 20 \%\end{array}$ \\
\hline $\mathrm{Ju}$ and Fan [33] & Polysilicon & & Sandstone & $\begin{array}{l}\text { Changed the wettability from oil-wet } \\
\text { to water-wet. TEM revealed that } \\
\text { nanoparticles where attached to the } \\
\text { pore wall }\end{array}$ \\
\hline Onyekonwu and Ogolo [7] & Polysilicon & $42-93$ & Sandstone & $\begin{array}{l}\text { Altered the wettability of LHPN, } \\
\text { HLPN and NWPN }\end{array}$ \\
\hline Villamizer et al. [77] & SWCNT & & & $\begin{array}{l}\text { Good stability at different } \mathrm{pH} \text { and } \\
\text { salinity }\end{array}$ \\
\hline Ju et al. [26] & IWWCA and IOWCA & 15 and $60-80$ & & $\begin{array}{l}\text { Using a physical model, mathemati- } \\
\text { cal model and numerical simulator }\end{array}$ \\
\hline Karimi et al. [31] & Zircon oxide & & Carbonate rock & $\begin{array}{l}\text { SEM and XRD verified change of } \\
\text { wettability }\end{array}$ \\
\hline Maghzi et al. [37] & Silica & 26 & Micromodel & Heavy oil \\
\hline Roustaei et al. [39] & Polysilicon & $28.5-32.2$ & & $\begin{array}{l}\text { Reduction in IFT from } 26.3 \text { to } 1.75 \\
\mathrm{mN} \mathrm{m}^{-1}\end{array}$ \\
\hline Baez et al. [53] & Amphiphobic and CNT & & & Reduction in IFT \\
\hline Hendraningrat et al. [56] & Silica & 4.5 & & $\begin{array}{l}\text { Reduction in IFT, solid phase more } \\
\text { wet }\end{array}$ \\
\hline Nguyen et al. [91] & Silica & 17 & & $\begin{array}{l}\text { Stabilized with } \mathrm{CO}_{2} \text { foam and more } \\
\text { stable than SDS }\end{array}$ \\
\hline Singh and Mohanty [90] & Silica & 10 & & Stabilized with Bioterage AS-40 \\
\hline Hendraningrat and Torsaeter [30] & Aluminium, silicon and $\mathrm{TiO}_{2}$ & $5-7$ & Berea sandstone & $\begin{array}{l}\text { Contact angle alteration decreases } \\
\text { towards more water-wet quartz }\end{array}$ \\
\hline Moustafa et al. [29] & Magnesium and aluminium & & & $\begin{array}{l}\text { Decrease the face contact angle from } \\
66^{\circ} \text { to } 60^{\circ}\end{array}$ \\
\hline Wan Sulaiman et al. [35] & Silica & $65.5 \%$ & Carbonate rock & $\begin{array}{l}\text { Silica altered the wettability at high } \\
\text { salinity }\end{array}$ \\
\hline Nazari et al. [36] & $\begin{array}{l}\mathrm{ZrO}_{2}, \mathrm{TiO}_{2}, \mathrm{MgO}, \mathrm{Al}_{2} \mathrm{O}_{3}, \mathrm{CeO}_{2} \\
\quad \mathrm{CNT}\end{array}$ & $8-9$ & Carbonate rock & $\begin{array}{l}\mathrm{CaCO}_{3} \text { and } \mathrm{SiO}_{2} \text { where used for the } \\
\text { flooding experiment }\end{array}$ \\
\hline Ragab and Hannora [58] & Alumina & $62-81$ & & Reduction in IFT \\
\hline Kim and Krishnamoorti [59] & $\begin{array}{l}\text { Poly (oligo (ethylene oxide) } \\
\text { Monomethyl ether methacrylate }\end{array}$ & & & $\begin{array}{l}\text { Reduced the IFT from } 50 \text { to } \\
20 \mathrm{mN} \mathrm{m}^{-1}\end{array}$ \\
\hline Griffith et al. [79] & Silica & 82 & Sandstone core & Stabilized with pentane water \\
\hline Kim et al. [80] & Hydrophilic silica & & Sandpack & $\begin{array}{l}\text { Generated strong and stable emulsion } \\
\text { with surfactant }\end{array}$ \\
\hline
\end{tabular}

formed by asphaltenes aggregates in the presence of resins which causes viscosity reduction in heavy oil [41]. Therefore, $\mathrm{ZrO}_{2}$ nanoparticles was reported by Wei and Babadagli [42] to have a potential to be used in the recovery of heavy oil (Tables 2, 3).

The nature of reservoir also plays an important role in determining the type of nanoparticles to be used. As all carbonate reservoirs are suggested to be oil-wet [43]. Therefore, the right nanoparticle and optimum concentration of the nanoparticle is required. $\mathrm{Al}_{2} \mathrm{O}_{3}, \mathrm{SiO}_{2}$ and $\mathrm{Fe}_{2} \mathrm{O}_{3}$ nanoparticles are effective for altering wettability of sandstone rocks [44]. Whereas $\mathrm{ZrO}_{2}$ and $\mathrm{NiO}$ nanoparticles are effective for Limestone formations [32]. $\mathrm{ZrO}_{2}$ was considered a better wettability modifier than $\mathrm{NiO}$, and it also exhibited a better performance than $\mathrm{SiO}_{2}$ and $\mathrm{Al}_{2} \mathrm{O}_{3}$ nanofluids $[32,45]$. Through microscopic imaging and theoretical calculations, the wettability alteration of $\mathrm{ZrO}_{2}$ is due to its deposition on rock surface which is governed by the partition coefficient of the nanomaterial in water and oil phase.

Hydration of nanoparticles is another major challenge encountered, ions within the clay material interact with the water leading to hydration and expansion of the $d$-space of the clay material [46]. To combat this problem, the use of swelling inhibitors should be employed. In formulating nanoparticles, the size control is very important for the success of EOR operations. The right size is needed to flow through the porous media, as large size will block the porethroat of the media leading to formation damage. Also, 
Table 2 Summary of the Flow Behaviour of Nanoparticles

\begin{tabular}{|c|c|c|c|}
\hline References & Nanoparticles used & Flow behaviour & Findings \\
\hline Tseng and Lin [127] & $\mathrm{BaTio}_{3}$ & Newtonian to Dilatant & $\begin{array}{l}\text { With distilled water and } \mathrm{NH}_{4} \mathrm{PA} \text { as the sur- } \\
\text { factant, when } \mathrm{NH}_{4} \mathrm{PA} \text { was added the suspen- } \\
\text { sion deviated from linear to dilatant }\end{array}$ \\
\hline Tseng and Lin [126] & $\mathrm{BaTio}_{3}$ & Pseudoplastic to dilatant & $\begin{array}{l}\text { In ethanol isopropanol with KD and PS-2 as the } \\
\text { dispersant, change the }\end{array}$ \\
\hline Maghzi et al. [37] & Silica & Pseudoplastic & A good match with power-law fluid \\
\hline Tseng and $\mathrm{Wu}[113]$ & $\mathrm{Al}_{2} \mathrm{O}_{3}$ & Shear thinning & $\begin{array}{l}\text { A transition from shear thinning to shear } \\
\text { thickening as the shear rate exceed } 100 \mathrm{~s}^{-1} \text {, for } \\
\text { double distilled water all suspension showed } \\
\text { shear thinning behaviour }\end{array}$ \\
\hline Tseng and Chen [114] & Nickel & Shear thinning & $\begin{array}{l}\text { Only with nickel shear thinning of all suspen- } \\
\text { sion, with -terpineol exhibited shear thinning } \\
\text { for particle suspension }\end{array}$ \\
\hline Prasher et al. [111] & Alumina, $\mathrm{Al}_{2} \mathrm{O}_{3}$ & Newtonian & Alumina/PG; $\mathrm{Al}_{2} \mathrm{O}_{3} /$ water; $\mathrm{Al}_{2} \mathrm{O}_{3} / \mathrm{EG}$ \\
\hline Tseng and Tzeng [128] & ITO & BINGHAM TO SHEAR THINNING & $\begin{array}{l}\text { In deionized water, with } \mathrm{NH}_{4} \mathrm{PA} \text { surfactant, } \\
\text { viscosity reduced by } 99 \% \text { at low shear rate } \\
\text { Bingham, change to shear thinning at high } \\
\text { shear rate }\end{array}$ \\
\hline Yang et al. [123] & NWCNT/poly-olefin oil & Shear thinning and Newtonian & $\begin{array}{l}\text { Dispersed in polyisobutane succinimide, } \\
\text { suspension with low and high concentration } \\
\text { exhibited shear thinning while at intermediate } \\
\text { was Newtonian }\end{array}$ \\
\hline Hong et al. [119] & $\mathrm{Fe}_{3} \mathrm{O}_{4}$ & Newtonian and shear thinning & $\begin{array}{l}\text { Newtonian at low concentration, shear thinning } \\
\text { at high concentration I deionized water }\end{array}$ \\
\hline Phuoc and Massoudi [120] & $\mathrm{Fe}_{2} \mathrm{O}_{3}$ & Newtonian and shear thinning & $\begin{array}{l}\text { In deionized water with PVP and PEO sur- } \\
\text { factant, PEO and PVP exhibited Newtonian } \\
\text { behaviour at low conc. and shear thinning at } \\
\text { high concentration }\end{array}$ \\
\hline Tamjid and Guenther [115] & Silver & Non-Newtonian & $\begin{array}{l}\text { Pseudoplastic at shear rate range of } 1-200 \mathrm{~s}^{-1} \\
\text { with silver/DEG }\end{array}$ \\
\hline Phuoc et al. [102] & NWCNT & Newtonian and shear thinning & $\begin{array}{l}\text { With deionized water in chitosan as the disper- } \\
\text { sant, at low concentration shows Newtonian } \\
\text { while at high conc. Shear thinning }\end{array}$ \\
\hline Esmaeilzadel et al. [96] & $\mathrm{ZrO}_{2}$ & Adsorption & $\begin{array}{l}\text { Addition of } \mathrm{ZrO}_{2} \text { to SDS surfactant increased } \\
\text { the adsorption onto fluid/fluid interface rather } \\
\text { than solid-liquid interface }\end{array}$ \\
\hline Abdelhalin et al. [116] & Gold & Newtonian & $\begin{array}{l}\text { Gold in water viscosity decreased with a rise in } \\
\text { temperature. }\end{array}$ \\
\hline Resiga et al. [122] & Magnetite & Newtonian & Magnetite in transformer oil \\
\hline Duan et al. [117] & Graphite & Shear-thinning & $\begin{array}{l}\text { Graphite in deionized water enhancement of } \\
\text { nanoparticle held for 3-days was higher than } \\
\text { freshly prepared one }\end{array}$ \\
\hline Moghaddam et al. [118] & Graphene & Shear thinning/Newtonian & $\begin{array}{l}\text { Shear thinning for at all temperature and low } \\
\text { shear rate. At high shear rate it was Newto- } \\
\text { nian, then thinning with increase in concentra- } \\
\text { tion }\end{array}$ \\
\hline Moatter and Cagincara [121] & $\mathrm{Fe}_{3} \mathrm{O}_{4}$ & Shear thinning & $\begin{array}{l}\mathrm{Fe}_{3} \mathrm{O}_{4} \text { in PEG all suspension showed shear- } \\
\text { thinning }\end{array}$ \\
\hline Zaballa et al. [101] & Alumina & Adsorption & $\begin{array}{l}\text { Alumina was used at reservoir condition with } \\
\text { Mirador-formation plug cores, production } \\
\text { increased by } 100,000 \mathrm{bbl}\end{array}$ \\
\hline Bayat et al. [97] & $\mathrm{Al}_{2} \mathrm{O}_{3}, \mathrm{TiO}_{2}$ & Retention & $\begin{array}{l}\text { Decline in recovery as a result of clay in the } \\
\text { porous media, position of clay at the pore- } \\
\text { throat caused trapping }\end{array}$ \\
\hline Cheraghain [137] & Fumed-silica & Pseudoplastic & Viscosity increased with weight of nanoparticle \\
\hline
\end{tabular}


Table 3 List of Studies on Oil Displacement Using Nanoparticles

\begin{tabular}{|c|c|c|c|c|}
\hline References & Nanoparticles used & Oil recovery (\%) & Rock type/porous media & Remark \\
\hline Onyekonwu and Ogolo [7] & LHPN, NWPN, HLPN & 42.9-93.13 & Sandstone & Total recovery \\
\hline Ogolo et al. [8] & $\begin{array}{l}\mathrm{Al}_{2} \mathrm{O}_{3}, \mathrm{MgO}, \mathrm{Fe}_{2} \mathrm{O}_{3}, \mathrm{NiO} \\
\mathrm{ZrO}_{2}, \mathrm{SnO} \text {, silicon }\end{array}$ & $18.3-30$ & Sandstone & Silicon was treated with silane \\
\hline Maghzi et al. [37] & Silica & 26 & Micromodel & Incremental recovery \\
\hline Mohammadi et al. [21] & $\gamma-\mathrm{Al}_{2} \mathrm{O}_{3}$ & 11.25 & Carbonate rock & Change in contact angle \\
\hline Maghzi et al. [37] & Silica & 10 & Micromodel & With polyacrylamide solution \\
\hline Joonaki and Ghanaatian [44] & $\mathrm{Fe}_{2} \mathrm{O}_{3}, \mathrm{Al}_{2} \mathrm{O}_{3}$, silica & 88.6-95.3 OOIP & Sandpack & Silica was treated with silane \\
\hline Charaghian [167] & Sodium bentonite nanoclay & 66.6 OOIP & Micromodel & Size of nanoclay is $50 \mathrm{~nm}$ \\
\hline Charaghian [168] & Nanoclay & 5.8 & Sandpack & Copolymerized \\
\hline Manan et al. [169] & $\mathrm{SiO}_{2}, \mathrm{CuO}, \mathrm{TiO}_{2}$ & $5-14$ & Sandpack & Used as a stabilizer in $\mathrm{CO}_{2}$ \\
\hline Nazari et al. [36] & $\mathrm{CaCO}_{3}, \mathrm{SiO}_{2}$ & $8-9$ & Carbonate rock & Incremental recovery \\
\hline Moradi et al. [170] & Silicon & $72-79$ & Carbonate rock & OOIP \\
\hline Sharma et al. [17] & Silicon & 60 cumulative & Berea sandstone & $\begin{array}{l}\text { Used as a stabilizer for surfactant AND } \\
\text { polymer }\end{array}$ \\
\hline El-Diasty [171] & Silicon & 35-50 OOIP & Sandstone & During breakthrough point \\
\hline Chen et al. [172] & MWNTs and CB & $41.7 \%$ & Sandstone & Cumulative recovery \\
\hline Singh and Mohanty [90] & Aluminium coated silica & $70-75$ & Berea sandstone & Cumulative recovery \\
\hline Alomair et al. [173] & $\mathrm{Al}_{2} \mathrm{O}_{3}, \mathrm{NiO}, \mathrm{SiO}_{2}, \mathrm{TiO}_{2}$ & $1-6$ & Berea sandstone & Incremental recovery \\
\hline Ragab and Hannora [58] & Silicon and aluminium & 7 & Berea sandstone & Incremental recovery \\
\hline Bayat and Junin [9] & $\mathrm{Al}_{2} \mathrm{O}_{3}, \mathrm{TiO}_{2}, \mathrm{SiO}_{2}$ & 48.7-52.6 OOIP & Limestone & $47.3 \%$ OOIP for water flooding \\
\hline Sulaiman et al. [48] & Silica & 65.5 & Carbonate rock & OOIP \\
\hline Cheraghian [137] & Titanium oxide & 4 & Sandstone & Increased viscosity of polymer \\
\hline Cheraghian [138] & Silica & 8.3 & Sandstone & Increased viscosity of polymer \\
\hline Jafernezhad et al. [174] & $\mathrm{SnO}_{2}$ & 61 OOIP & Carbonate core plug & $\begin{array}{l}\text { Nanoparticle-altered wettability and } \\
\text { reduced IFT }\end{array}$ \\
\hline Azarshin et al. [175] & Silica & 18 & Iranian reservoir core & $\begin{array}{l}\text { Modified Silica surface was more } \\
\text { effective }\end{array}$ \\
\hline Zallaghi et al. [176] & Silica & 11.7 & Sandstone core & \\
\hline Youssif et al. [177] & Silica & 13.28 & Sandstone & $\begin{array}{l}\text { Low concentration decreased perme- } \\
\text { ability }\end{array}$ \\
\hline Nwidee et al. [32] & $\mathrm{ZrO}_{2} ; \mathrm{NiO}$ & & Limestone & Altered wettability and reduced IFT \\
\hline
\end{tabular}

nanoparticle retention and entrapment must be prevented to the barest minimum for a successful wettability alteration to be achieved.

\section{Interfacial tension (IFT) reduction}

The main mechanism is the migration and arrangement of the oil-water interface, which is dependent on the hydrophobic and hydrophilic properties of the nanoparticles. The purpose of surfactant flooding is to increase the capillary number by reducing IFT between the oil and water [1, 47]. Nanofluids of 70-150 nm dissolved in aqueous solution of surfactants can result in effective oil displacement of $35 \%$ compared to using only surfactants in a homogeneous reservoir, and $17 \%$ in a heterogeneous reservoir at a temperature of $25^{\circ} \mathrm{C}$. The increase in recovery because of lowering of IFT occurs when the fluid changes characteristics from Newtonian to non-Newtonian state [48].

\section{Mechanism of IFT reduction}

IFT is used to determine nanofluid movement in porous media, it is important to determine the IFT between the oil and fluid in EOR technique. The pendant drop and the spinning drop methods are widely used to measure IFT. The theory behind the mechanism of operation in nanoparticles IFT tension is still under debate, but to get a good insight into the working mechanism between the nanoparticles, rock and fluid. The Poisson-Boltzmann and Derjaguin-Landau-Verwey-Overbeek (DLVO) theory of approximation are used. Be that as it may, to understand the forces in play, the particle size, the force of attraction and DLVO theory must be considered.

Particle size The morphology of particles as well as the area to volume ratio for the particle molecule to interact with fluid molecules is an important aspect that governs surface 
tension in a complex fluid. Near-spherical morphologies has a minor increment in the interfacial energy compared to hexagonal pillar and flake-like morphologies. Therefore, surface tension of nanofluid also shows slight increment with size [49]. Nanoparticles have high surface to volume ratio with high contact area. These enable a high diffusion rate, mass transfer which can change the properties of fluid [50]. Nanoparticles can be measured in microscale that is, they have the tendency to spread homogenously in porous media, reaching corners that originally were not touched by conventional methods. The polarity of fluid can also affect surface tension of nanoparticles according to the electric double layer (EDL) formed at the particle-fluid interface. The particles at the interface will experience a weaker repulsive force from the particles in the bulk. There is a tendency of desorption to the bulk from the interface leading to no appreciable change in surface tension. This might be because of high viscosity of the fluids. Particles Brownian motion might have been partially hindered and the particles finds it difficult to adsorb from the bulk to the interface and vice versa.

The governing mechanism is a multiphase zone comprising of the interface of the solid nanoparticles, the suspended base fluid and the coexisting interface. The surface energy associated with each of these interfaces depends on the characteristics of the nanoparticles suspended, the base fluid of the suspension and the surrounding fluid region [49]. The bulk surface tension of the resulting suspension is determined by the collective interaction of the vector additions of the forces at the microscopic and the summation of such interaction. The hydrophilic or hydrophobic nature of the particles is the driving force that determines the affinity of the particles towards one of the phases [51]. The particles affinity towards the surface is a strong function of the equilibrium interface contact angle, which favours the particles partial wetting behaviour. The mechanical agitation of the particles at the fluid-air interface is shown in Fig. 3. The particle must satisfy the minimum energy criteria to be positioned at the interface with height $(h)$ protruding out from the fluid interface as shown in Fig. 3. Creating a localized contact angle $(\theta)$, which is the point of stable equilibrium made by the particles at nanoscale three-phase contact point [49]. Whereas the particle radius is $(r)$ and the radius of the interface area of the fluid occupied by the solid particle is (b).

Electrical layer As the reservoir is said to have a charged surface, so also is the rock surface which is considered to have a constant net charge, positive forces are arranged at the rock surface while negative forces in the fluid interface, ignoring the gravitational forces working on the nanoparticles for pronouncement of the charged forces, this region of opposite charge is referred to as the EDL. The

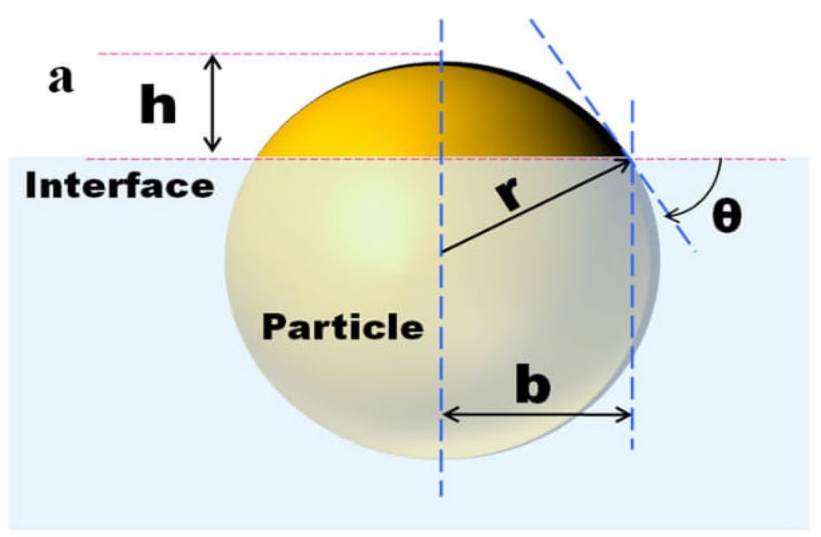

Fig. 3 Schematic representation of nanoparticles at fluid air interface [49]

Poisson-Boltzmann equation is used to predict nanoparticle flow behaviour in porous media at charged interface [50], which is expressed as;

$\nabla^{2} \psi=\frac{2 Z e n_{0}}{\varepsilon} \sinh \left(\frac{s e}{K_{\mathrm{B} T}}\right)$,

whereas $\psi$ is the electric potential, $z$ is the axis perpendicular to the surface, $e$ is the charge of the electron, $n_{\mathrm{o}}$ is the particle concentration, $\varepsilon$ is the permittivity, $h$ is the height of nanochannel, $s$ is the cross section, $K_{\mathrm{B}}$ is the Boltzmann constant, $T$ is the temperature.

Most colloidal particles are surrounded by EDL. It can be assumed that nanoparticles suspended in the base fluid in the form of colloidal particles are surrounded by EDL. The force of attraction and repulsion are exerted on the nanoparticles [52]. The force of attraction is governed by van der Waals forces, which induces coalescence of the particles if the distance between the particles exceeds the energy barrier. Whereas the force of repulsion is governed by Coulombs force, which prevents coalescence of the particles [52]. The distance of the EDL can determine the amount of Coulomb force acting on the nanoparticles. As sufficient Coulomb force is needed to act on the nanoparticles to attain a stable nanofluid [53].

DLVO theory DVLO theory states that the stability of two particles in close proximity is dependent on the total energy of their interaction. It considers the forces of attraction and repulsion between the nanoparticles, rock and fluid such as van der Waals attraction, EDL, born repulsion, acid-base interactions and hydrodynamic forces [9]. Based on DLVO modelling, the basic assumption is that the particles are spherical, which does not hold for all manufactured nanoparticles as some are rod-like, triangular, polygonal. The force of attraction between these 
particles differs and there is need to reduce the electrostatic repulsion between the nanoparticle building block [54]. Therefore, the small size and large surface area of nanoparticles conflicts with the fundamental assumptions of DLVO theory leading to series of challenges. When particles reach a small size, it surfaces curvature becomes too substantial enough to assume it is flat, which becomes a problem when considering its aggregation with respect to DLVO theory. This is because as the size of the particle decreases, high number of the atom exist at the surface which will affect the electronic structure, surface and reactivity charge [55]. The chemical composition of most material can also pose a problem to this theory, as some ferromagnetic materials like iron and magnetite can cause magnetic attraction without a magnetic field which can lead to rapid aggregation. Therefore, the shape and size of nanoparticles can control nanoparticle aggregation and should be taken into consideration when manufacturing nanoparticles.

Roustaei et al. [39] measured the IFT and wettability of polysilicon nanoparticles, using hydrophilic and hydrophobic polysilicon (HLP) and naturally wet polysilicon (NWP). They reported a reduction in the IFT from 26.3 to $1.75 \mathrm{mN} \mathrm{m}^{-1}$ and, oil recovery increased to 32.2 and $28.5 \%$ with $4 \mathrm{~g} \mathrm{~L}^{-1}$ of HLP and NWP, respectively. Hendraningrat et al. [56] also reported that hydrophilic silica nanoparticles can reduce IFT between water and oil phase and make the solid phase more wet, the nano fluid increase the oil recovery about $4.5 \%$ compared to brine flooding.

Baez et al. [57] used a novel amphiphobic nanoparticlebased functionalized CNT and they were very effective in reducing IFT.

Ragab and Hannora [58] using alumina in flooding experiment had a recovery in the range of $62-81 \%$, the reason was due to the reduction in IFT of the nanoparticles.

Kim and Krishnamoorti [59] studied the behaviour of water soluble poly oligo (ethylene oxide) monomethyl ether methacrylate. The synthesized nanoparticles reduced the interfacial tension from 50 to $20 \mathrm{mN} \mathrm{m}^{-1}$ at a concentration of $1-100 \mathrm{ppm}$.

\section{Comparative study on the effect of surfactant and nanoparticles on IFT reduction}

The use of surfactant to reduce IFT tension has its own limitations, in this section, an attempt is made to compare these limitations with the solutions nanoparticles can provide vis-a-vis their effects. The mechanism of surfactant and nanoparticles is to reduce IFT, in surfactant flooding, this is closely related to solubilisation of oil and water. On like nanoparticles which uses the Poisson-Boltzmann equation and DLVO theory, surfactant uses the Healy and Reed correlation equation and the Huh equation to understand the relationship between the IFT and solubilisation. Factors such as concentration of surfactant, salinity, temperature, divalent ions, and formation can affect IFT $[1,60]$.

Effect of formation The high adsorption rate of anionic surfactant in carbonate reservoir coupled with the high cost of cationic surfactant has made the application of surfactant flooding to be limited to sandstone reservoirs and only few applications in carbonate. But Bayat and Junin [9] reported that nanoparticles of $\mathrm{Al}_{2} \mathrm{O}_{3}, \mathrm{TiO}_{2}$ and $\mathrm{SiO}_{2}$ were able to recovery $52.6,50.9$ and $48.7 \%$ OOIP, respectively in limestone porous media. These high recoveries were attributed to the nanoparticles mobility. Also, the magnitude of the EDL repulsion in comparison with the London-van der Waals attraction between the formation was greatly diminished when nanoparticles propagated through the porous media [61]. Godinez and Darnault [62] believed that deposition process is a key retention mechanism of nanoparticles. This because, as the solution $\mathrm{pH}$ of nanoparticles approach point of zero charge, the mobility and transport of the nanoparticles will be limited. This is due to the reduction of electrostatic interaction forces, leading to the increase in the deposition rate. Whereas $\mathrm{Ju}$ and Fan [33] reported that adsorption of nanoparticles at pore walls and pore throat blocking is high close to the inlet of the porous media. The control of particle size during injection and reaction times of nanoparticles inside the porous media is very important. This is because the size of the particles could reduce the pressure through permeability reduction. Also, particles size could impact on dispersion ability, adsorption affinity and catalytic activity of nanoparticles inside the medium [14].

Effect of salinity and divalent ions Surfactant tends to precipitate at high salinity and for most surfactants the optimum salinity is not high and as such, divalent may be associated with it, thus affecting surfactant performance [63]. Wan Sulaiman et al. [35] reported the use of hydrophilic silica nanoparticles in oil-wet limestone at different nanofluid concentration with different formation brine concentration. A high recovery of up to $65.4 \%$ OOIP by lowering of the IFT was reported. Figure 4 shows the oil recovery at different concentration of brine with nanofluid.

Bayat and Junin [9] concluded that the mobility of nanoparticles through porous media strongly depend on the stability, porous media surface charge and roughness. This implies that nanoparticles with the same surface charge as the porous media are more stable against deposition and can easily be transport through the porous media. Whereas those with opposite surface charge will lead to noticeable adsorption on the porous media. 


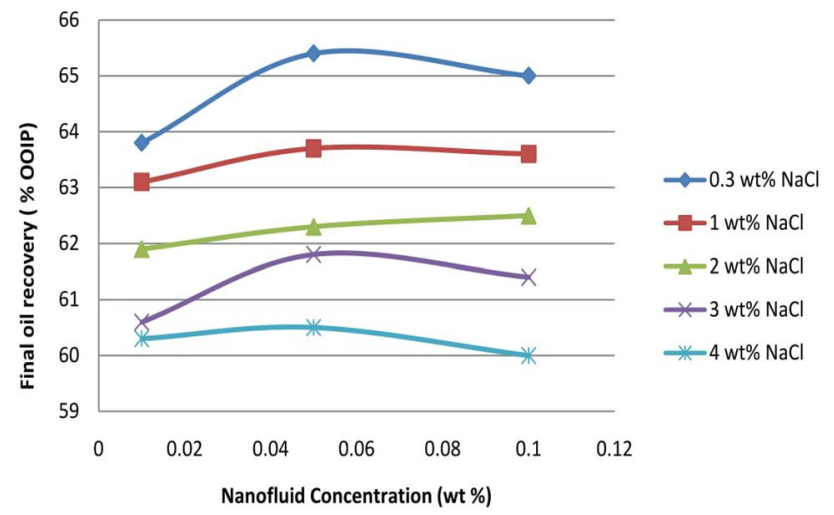

Fig. 4 Oil recovery at different concentration of brine with nanofluid [35]

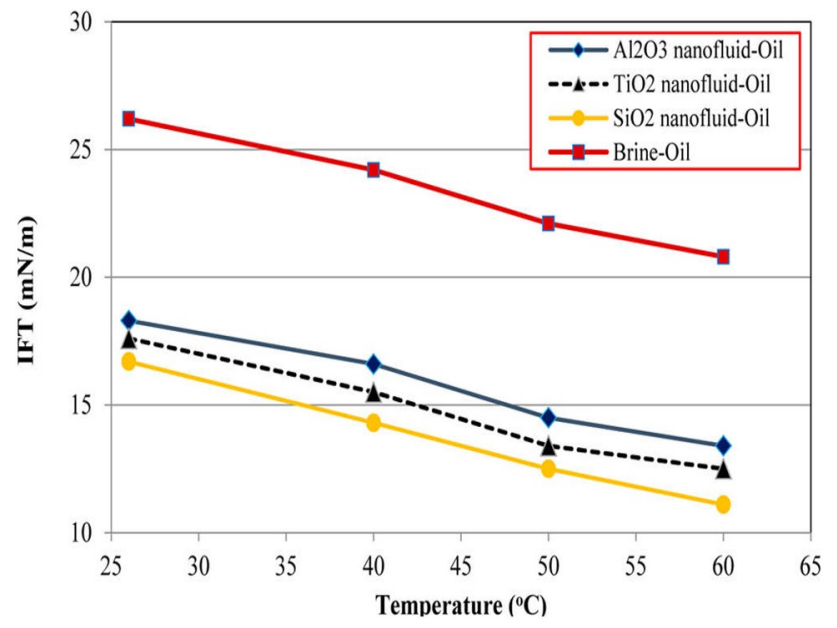

Fig. 5 IFT of oil/aqueous phase at different temperatures and at ambient temperature [65]

Effect of reservoir temperature Surfactant also precipitate at high temperature, the median temperature for the surveyed surfactant project is $25.3{ }^{\circ} \mathrm{C}$ [47]. Ranka et al. [64] stabilized nanoparticles at high-temperature reservoir condition. They reported the use of hydrophilic silica and hydrophobic polystyrene nanoparticles to achieve a long-term colloidal stability up to twice the stability limit previously reported in open literature. Bayat et al. [65] demonstrated that using $\mathrm{Al}_{2} \mathrm{O}_{3}, \mathrm{TiO}_{2}$ and $\mathrm{SiO}_{2}$ nanofluid can reduce IFT by 33,37 and $42 \%$, respectively compared to brine. The reduced trend was observed for all temperatures as shown in Fig. 5. This shows that nanoparticles have low affinity to be adsorbed compared to surfactants. The low adsorption rate can lead to increased oil recovery. The mechanism in play is the decrease in capillary forces, by the deformation of the trapped oil droplets.

\section{Challenges of nanoparticles in reducing IFT}

At lower surfactant concentration, addition of nanoparticle reduces IFT but, at higher concentration, IFT increases when nanoparticles are added. This can be attributed to the electrostatic repulsive interaction between the nanoparticles and the surfactant that promoted the diffusion of the surfactant towards the interface [66]. Nanoparticles can act as a carriers of surfactant molecules towards the interface, but at high concentration the nanoparticles attract the surfactant molecules which can lead to aggregation of the surfactant molecules [67]. One of the major challenges of nanomaterial design is the control of colloidal stability of the particles to prevent aggregation and damaging interaction with the surrounding, as tiny particles tends to aggregate and form bigger particle cluster. This is due to the surface energy as a result of high surface energy of the nanoparticles which might lead to adsorption of other particles or molecules on the surface. This might change the physical and chemical properties of the nanoparticles making it less effective in reducing IFT. The hydrating layer surrounding each nanoparticles act as a repulsive barrier which prevents the nanoparticles from attaching to each other due to the attractive van de Waals forces. Therefore, at lower linker concentration both spherical and rod-like nanoparticles tend to form linear chains because of the need to reduce the electrostatic repulsion between the building blocks of the nanoparticles. When the concentration of the linkers is increased the attachment is no longer linear [54]. Interfacial interaction between two faces in a hybrid solution is the most decisive factor affecting the properties of the resulting material. Therefore, the dispersion of the nanoparticles is of great importance to the properties of the nanoparticles as such surface modification with active functional groups can optimize the efficiency of the process [68].

\section{Nanoemulsions in EOR}

Nanoemulsion have drop length-scale less than $100 \mathrm{~nm}$, they can retain their morphology with the change in oil volume fraction. The ease of nanoemulsion preparation stability and increased bioavailability are the main features of their formulation which have attracted researchers [69]. They are basically three types of nanoemulsion; oil in water emulsion where, oil droplets are dispersed in the continuous aqueous phase. Water in oil emulsion where, water droplets are dispersed in the continuous aqueous oil phase. And bi-continuous nanoemulsion where, micro domains of oil and water intersperse within the system. The characteristics of nanoemulsion that makes them attractive for EOR application includes; their lack of shear-thickening and sedimentation problem. This is because of their small size. Nanoemulsion have high dispersibility compared to microemulsion. Their 
small size droplet can prevent flocculation. And they are easily stabilized against Brownian collision with a polymeric surfactant that produces steric repulsion [70].

\section{Application of nanoemulsion in EOR}

Nanoemulsion are suited for large-scale field applications, this is because they can penetrate through pore throats without retention [71]. This attribute of nanoemulsion, has had a huge impact on EOR mechanism as residual oil is recovered from the reservoir. Small drop size of nanoemulsion which is usually smaller than the pore throat in gravel-pack and reservoir rock can result in good injectivity and penetration without filtration [72]. This can prevent the issue of gravitydriven separation due to the density difference of the two phases. Binks et al. [73] also reported that nanoemulsion can withstand harsh reservoir condition of high pressure, temperature, shear and salinity. Therefore, nanoemulsion can remain stable in the reservoir at these prevailing conditions.

\section{Effect of nanoparticles on stability of emulsion}

Emulsion when generated in situ or injected have the capacity to divert flow to the by-passed oil by blocking swept out pores [74]. It also helps to entrain oil into the mobile aqueous phase which will lead to a better sweep efficiency. Studies have also shown that emulsion can increase viscosity and decrease mobility ratio, which will in turn lead to increased recovery [75]. Surfactants are mostly used to stabilize emulsion but under harsh reservoir condition, surfactant emulsion has its limitations and its high mobility ratio cannot be controlled. Nanoparticles can be used to stabilize emulsion and is more advantageous than surfactants. Droplet images of emulsion made with $0.1 \mathrm{wt} \%$ cetyl trimethylammonium bromide (CTAB) and various nanoparticle concentration is shown in Fig. 6.

Nanoparticles have significant effect on the displacement dynamics of wetting and non-wetting phases, in situ emulsion takes place when octane displaces brine containing nanoparticles. Nanoparticle stabilized emulsion can also stabilize oil front, but the physics behind the non-wetting and wetting phase imbibition is different for nanoparticles dispersion displacement process. The coated nanoparticles could accumulate at the displacement front at the oil-water interfacial area because of the lipophilic nature of the nanoparticles. Nanoparticle can seriously affect the phase behaviour of oil-water system, nanoparticle-induced toluene-inwater and crude oil-in-water emulsions are stable at elevated

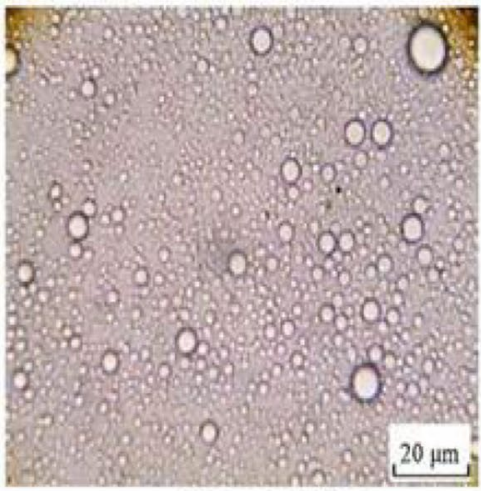

(a) $0.01 \% \mathrm{~N} 20$

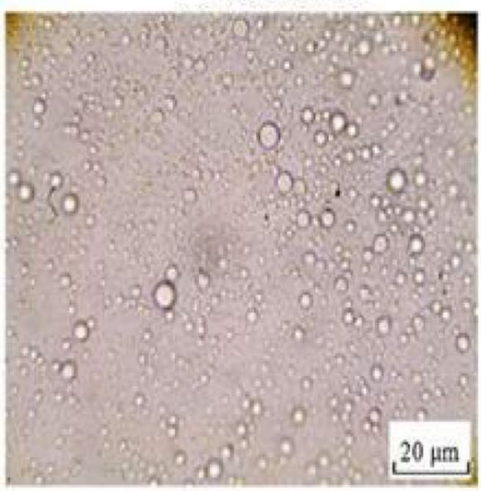

(d) $0.3 \% \mathrm{~N} 20$

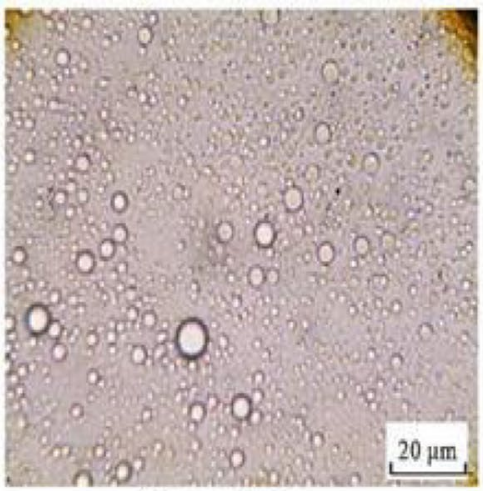

(b) $0.1 \% \mathrm{~N} 20$

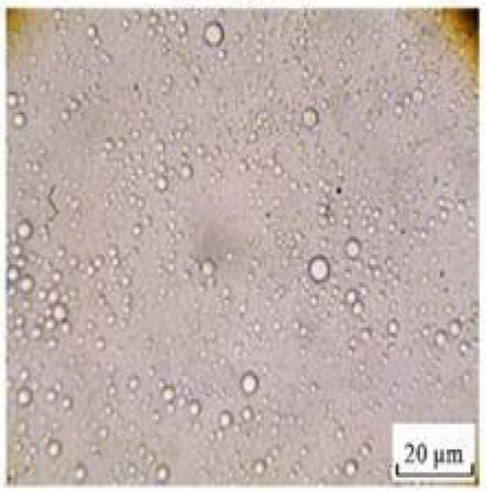

(e) $0.4 \% \mathrm{~N} 20$

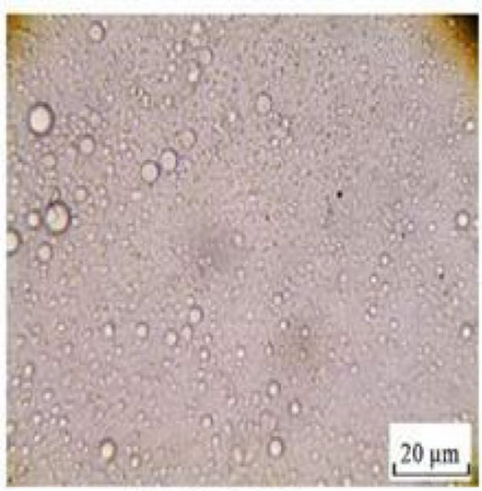

(c) $0.2 \% \mathrm{~N} 20$

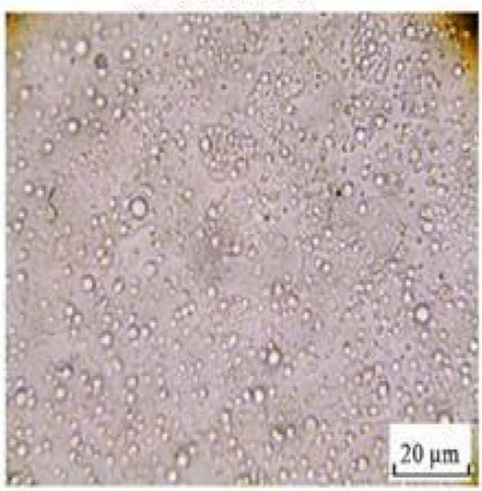

(f) $0.5 \% \mathrm{~N} 20$

Fig. 6 Droplet images of emulsion made with $0.1 \mathrm{wt} \%$ CTAB and various nanoparticle concentration [74] 
temperature. This was achieved by the short-chain polyethylene oxide polymer with silane end group which coated over the nanoparticles. But other hydrocarbon like hexane, decane and mineral oil are not able to form stable emulsions. The concentration of salt and concentration nanoparticles has opposite effects on the stability of emulsion. Viscous emulsion is more stable and are very important for oil recovery [76].

Villamizer et al. [77] studied the stability of silica nanohybrid single wall carbon tube (SWCNT) in EOR. They reported that the hybrid shows good stability at different $\mathrm{pH}$ and salinity. Low concentration of nanoparticles can stabilize emulsion for months which has a potential application in EOR.

Pei et al. [78] showed that nanoparticles-surfactant stabilized emulsion was able to recover heavy oil by making emulsion thick and achieved desired mobility that can improve the sweep efficiency. In their experiment using a micro-model as the porous media, they reported a recovery of $40 \%$ of OOIP.

Griffith et al. [79] in their work on Boise sandstone cores with silica nanoparticles-stabilized pentane in water (natural gas liquid-emulsion) as the injecting fluid, while light oil was the residual oil, the result showed up to $82 \%$ residual oil recovery.

Kim et al. [80] studied the synergy's benefit of employing nanoparticles in emulsion for improved mobility control especially under high salinity control using hydrophilic silica nanoparticles and surfactant in oil-in-brine emulsion formation. They successfully generated a strong and stable emulsion with a combination of either cationic or non-ionic surfactant with nanoparticles compared to surfactant and nanoparticles themselves alone.

The combination of two or more nanoparticles can be employed to stabilize emulsion. McClements and Jafari [81] reported that the combination of two different emulsifier may lead to the formation of emulsion with different droplet size and has a better stability compared to when used separately. Using mixture emulsifier during homogenization process can reduce the size of the droplet produced. This is because one of the emulsifier may adsorb quickly and reduce the IFT. But may be less effective in stabilizing the droplet against coalescence. Whereas the other emulsifier may be less effective at reducing IFT but, maybe very effective in impeding droplet coalescence.

\section{Foam stability using nanoparticles}

The change in height of form generated with time and the time taken by the foam to reach half of its original life is a measure of its stability. The rate of foam collapsed can decrease with increasing surfactant concentration. However, foam stability only increases with increase in surfactant concentration. The type of nanoparticle and the concentration of the nanoparticles are the two influential parameters on the stability of foam and the nanoparticle suspension. Which can be made to have a better stability thereby, prolonging the generated lifetime of the foam [82]. $\mathrm{SiO}_{2}$ and $\mathrm{Al}_{2} \mathrm{O}_{3}$ nanoparticles were reported by Bayat et al. [82] to have high foam stability based on the foam half-life time, and a direct relationship between the nanoparticle stability against deposition in aqueous phase and foam stability. Therefore, the stability of the nanoparticles against deposition in the aqueous phase before it is utilized for fabrication of foam was also an important factor in stabilizing $\mathrm{CO}_{2}$ foam with nanoparticles. This was observed when the nanoparticles affected the morphology and size of the foam bubbles as the shape changed from polyhedral to spherical and the size of the bubbles becomes smaller and uniform [82]. But in the presence of oil, foam stability depends mainly on the viscosity and density of the oil [83]. The addition of nanoparticles will increase the stability due to aggregation of the nanoparticles at the thin Lamella of the foam (Fig. 7), which prevented spreading of the oil at the gas-liquid interface. The modification of silica-sodium dodecyl sulfate (SDS) mixture resulted in optimum foam stability, whereas the slower liquid drainage from the foam did not result in high foam stability. Nanoparticles when used to stabilize foam, can withstand high temperature reservoir condition, at low concentration, nanoparticles can be used to stabilize foam, but at high salinity, the stability of foam decreases [84]. This was observed by Yekeen et al. [85] when they noticed that the foam stability decreased in the presence of salt until the transition salt concentration was reached. Beyond the transition salt concentration, the foam stability will increase with the increasing salt concentrations [85]. The dominant mechanisms of the foam flow process were lamellae division and bubble to multiple bubble lamellae division as shown in Fig. 7. These mechanisms dominated the residual oil mobilization and displacement by the foam and it was found to be a directly proportional to the displacement and emulsification of the oil as shown in Fig. 8. In a water-wet system (Fig. 8), the dominant mechanism of the flow process and residual oil mobilization are lamellae division and emulsification oil, respectively, but in the oil-wet system, the generation of pore spinning continuous gas foam was the dominant mechanism governing the foam flow process and residual oil mobilization [86]. In the generation of $\mathrm{SiO}_{2}-\mathrm{SDS}$ and $\mathrm{Al}_{2} \mathrm{O}_{3}-\mathrm{SDS}$ foam, the pore level mechanism controlling the behaviour of the nanoparticle-surfactant foam in the porous media are similar which led to improved foam dynamic stability in water-wet and oil-wet porous media [86].

Generally, the performance of foam was enhanced with increasing nanoparticle hydrophobicity which increases stability but decreases foamability with increasing concentration of the nanoparticles. Therefore, nanoparticles increase 


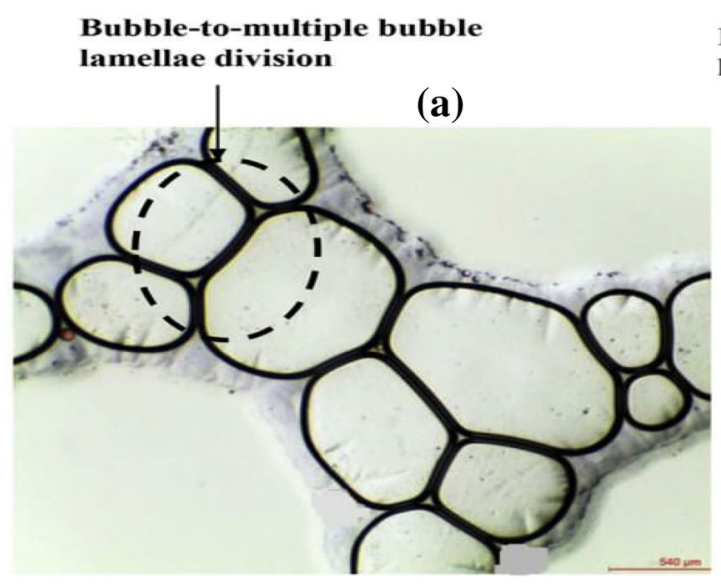

\section{Bubble-to-multiple bubble lamellae division}

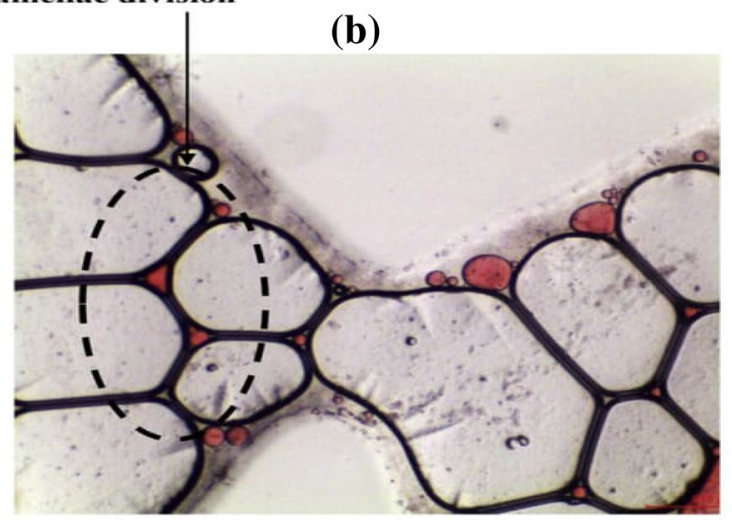

Direction of foam flow

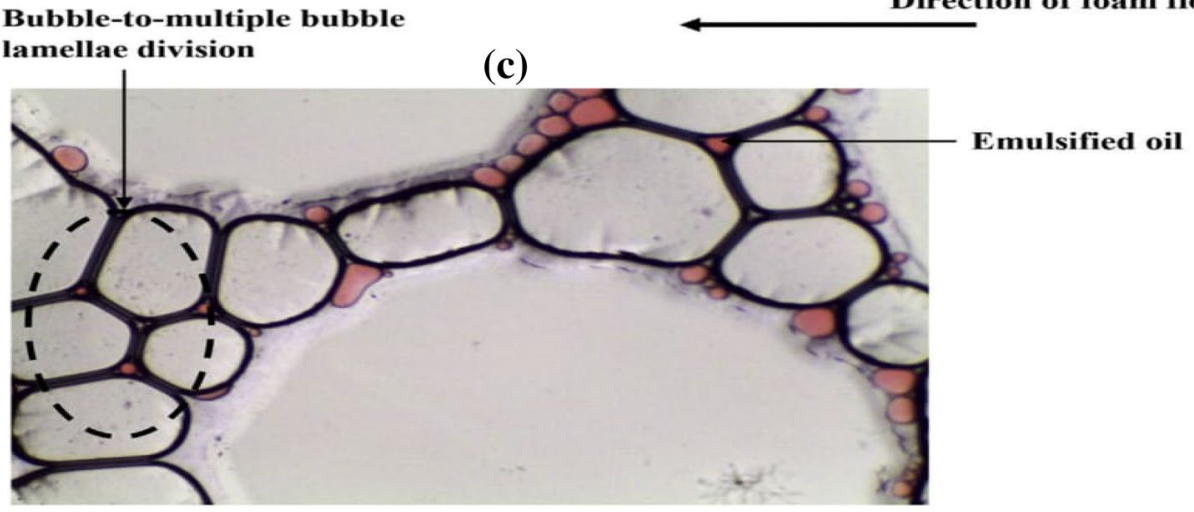

Fig. 7 Occurrence of bubble-to-multiple-bubble lamellae division, a $\mathrm{SiO}_{2}-\mathrm{SDS}$ foam flow in the absence of oil, $\mathbf{b} \mathrm{SiO}_{2}-\mathrm{SDS}_{\text {foam flow }}$ process in the presence of oil, $\mathbf{c ~} \mathrm{Al}_{2} \mathrm{O}_{3}$-SDS foam flow process in the presence of oil [85]

foam apparent viscosity, improves foam stability by adsorption and aggregation at the foam lamellae which increases the film thickness. And dilatational viscoelasticity which prevents liquid drainage and film thinning leading to bulk and bubble scale stability [87].

Experimental results show that foam can be generated at a critical shear rate higher than $4000 \mathrm{~s}^{-1}$ [87]. But using dynamic experiment to produce foam by nanoparticle dispersion with $\mathrm{CO}_{2}$ injection in a glass bead column, stable form was formed at shear rate higher than $1419 \mathrm{~s}^{-1}$ at 1500 psig. Increase in the injection rate increased the shear rate to $3312 \mathrm{~s}^{-1}$, and increased viscosity from 1.5 to 2.5 times higher than the normal dispersion without foam [88].

$\mathrm{Yu}$ et al. [89] applied nanoparticle stabilized $\mathrm{CO}_{2}$ foam to improve oil recovery in high and low permeability core after water flooding, they reported a $48.7 \%$ recovery in a $33 \mathrm{mD}$ permeability and $35.8 \%$ in a $270 \mathrm{mD}$ permeability.

Singh and Mohanty [90] studied foam stabilization with silica nanoparticles and Bioterage AS-40 surfactant for EOR. They reported that the concentration of nanoparticles is important for foam stability, which increases the recovery by $10 \%$ of OOIP. Also, Nguyen et al. [91] controlled the mobility in EOR using nanoparticle stabilized $\mathrm{CO}_{2}$ in water foam using microfluidic method. Their report shows that coated silica nanoparticle stabilized $\mathrm{CO}_{2}$ foam is more stable than SDS, which recorded an additional $17 \%$ oil after water flooding.

Mo et al. [92] reported increase in recovery from 64.9 to $75.8 \%$ when pressure was increased from 1200 to 2500 psi but an increase in temperature reduced the recovery when working with nanosilica-stabilized $\mathrm{CO}_{2}$ foam.

\section{Nanoparticle flow behaviour in porous media}

Nanoparticles must be able to flow deep into the reservoir to assist in oil displacement, studies have shown that some challenges are encountered in the flow of nanoparticles in porous media $[93,94]$. Therefore, the need to understand the mechanism affecting the flow of nanoparticles in porous media is of importance. The emphasis here will be on the physical aspect of the flow, the microscopic rheological behaviour and the adsorption of the nanoparticles in porous 


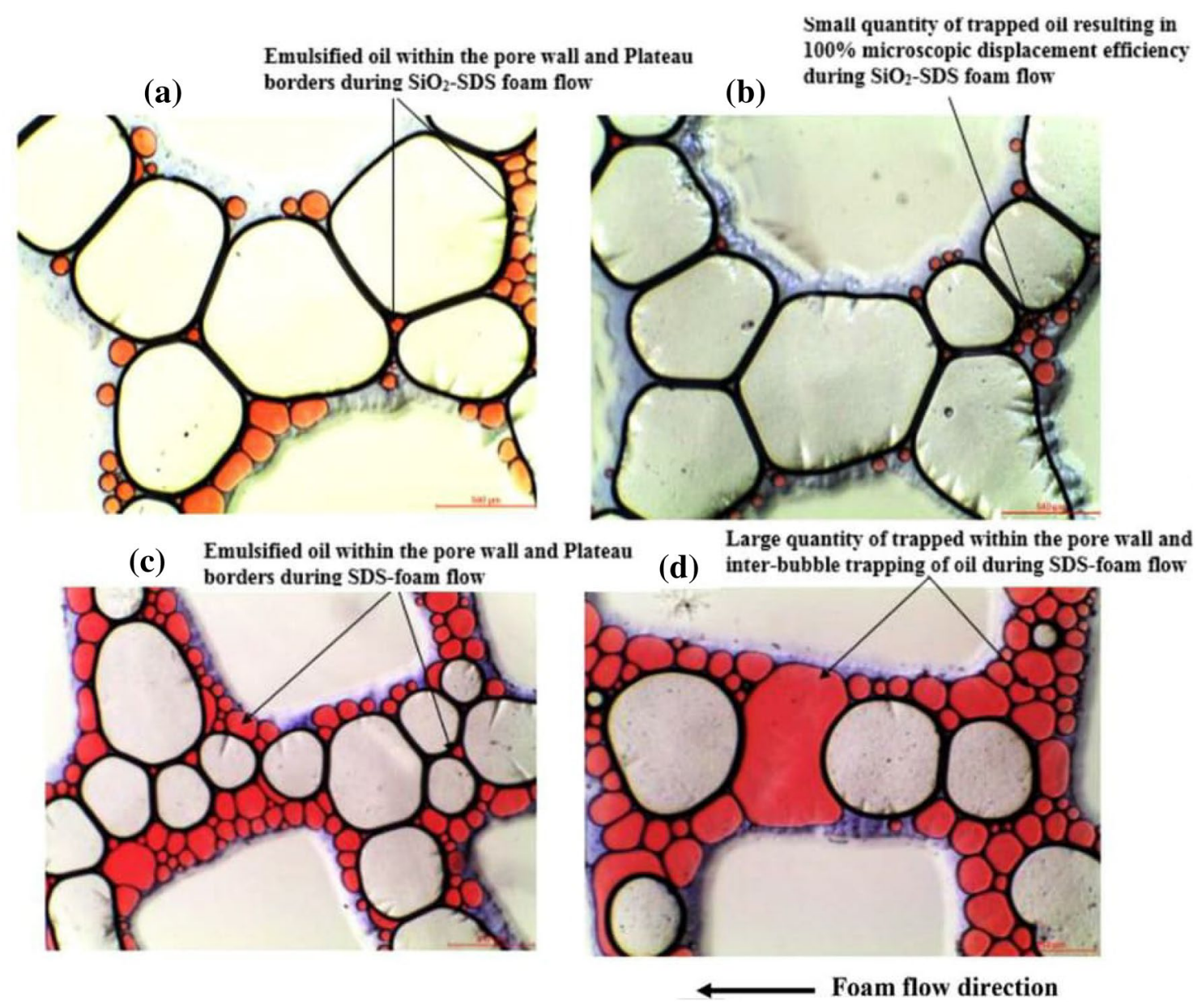

Fig. 8 Mechanism of residual oil mobilization in water-wet system, a emulsification of oil during $\mathrm{SiO}_{2}$-SDS foam flow, $\mathbf{b}$ effective emulsification, $\mathbf{c}$ oil emulsification, $\mathbf{d}$ inter-bubble trapping and oil trapping at the pore walls [86]

media. The transparent visualization of fluid flow through porous media and the mechanism that takes place during oil recovery by nanoparticle or nanoparticle retention in porous media can be well understood by microfluidic approach using lab-on-a-chip approach, and by macro and micromodel experiments.

\section{Nanoparticle filtration}

This occur when the particles are larger than some of the pores in the porous media, especially when nanoparticles are co-polymerized or with surfactants. This may also occur for non-aggregated nanoparticles when injected in low permeability rocks (tight sandstones). Therefore, the size and shape of the nanoparticles are important parameters that can affect filtration. It is important to note that filtration can be initiated by the larger particles, which will cause further filtration, which may lead to decrease in size of the pores after initial filtration [57].

\section{Nanoparticle adsorption in porous media}

The flow of nanoparticles through porous media exhibit a Brownian motion, due to the size of the particles, several forces like the Van der walls forces attracts potential forces and control the interaction between the nanoparticles and the porous media walls [95]. Adsorption and desorption takes place depending on the attraction and repulsion force between the porous media wall and nanoparticles. During the flow of nanoparticles through porous media, mainly diffusion, convection and hydrodynamics play major role [34]. However, the adsorption of nanoparticles onto rock surface is influenced by born repulsion and controlled by hydrodynamic forces.

1. Born repulsion: the adsorption of nanoparticles onto the surface is influenced by the born repulsion which occurs because of the coming together of the nanoparticles surface and the walls of the pores of the media. 
2. Hydrodynamic force: the hydrodynamic force controls the suspension of a flowing liquid, when the nanoparticles flows through porous media, if the hydrodynamic forces are low, the particles will be suspended onto pore surface and might get adsorbed depending on the surface charge.

Adding nanoparticles into chemical slugs reduce adsorption. These happen during the interaction of chemicals and the rock surface, hydrogen bonding, covalent bonding, hydrophobic bonding and solvation of various species. Therefore, it is a necessity to prevent this interaction, EOR chemical adsorbs at solid-liquid interface by transferring molecules from solution phase to the solid-liquid interface. This only happens when the molecules are favoured in comparison to the bulk phase. Micellization starts to form at higher concentration and form hemimicelles with one or two layers [60]. The solid surface adsorption starts to increase until a bilayer is formed on the solid surface. Addition of nanoparticles helps the molecules at the liquid-liquid interface and affect the interfacial and adsorption behaviour of the process [96, 97]. Even when nanoparticles are of the right size and stable in solution, adsorption can also impede their transportation through porous media. The less the nanoparticles are adsorbed, on the rocks, the economics of oil recovery is improved [98]. Studies have shown that when nanoparticles are coated with polymer, it results to stable particles in solution, but it can also lead to high adsorption and retardation of nanoparticles when injected into the porous media $[99,100]$. The electrostatic repulsion and the hydrophobic and hydrophilic interaction between the nanoparticles and the rock can reduce adsorption. Nanoparticles with favourable surface charge that matches that of the rock may exhibit less adsorption [100].

Esmaeilzadel et al. [96] studied the adsorption of anionic, cationic and non-ionic surfactant on carbonate rock in the presence of $\mathrm{ZrO}_{2}$ nanoparticles. They reported that adding $\mathrm{ZrO}_{2}$ to SDS surfactant increases the adsorption onto fluid/ fluid interface rather than solid-liquid interface.

Zabala et al. [101] investigated the adsorption capacity of alumina nanoparticles at reservoir condition with Miradorformation plug cores. They reported a remarkable increase in production 100,000 bbl cumulative production in 4 months, by injecting nanoparticles suspension into a glass model. Hendraningrat et al. [102] investigated nanoparticles retention in porous media. From the result of the visualization experiment, they concluded thus; that nanoparticles were deposited and adsorbed at the surface, which led to reduction in permeability by blocking the pore throat of the model.

$\mathrm{Li}$ and Torsaeter [34] investigated the performance of nanoparticles in oil recovery, they reported that adsorption of nanoparticles in glass micro model may cause plugging of the channel and thereby reduce permeability by changing the pressure drop during the experimental process.

Bayat and Junin [9] studied the influence of clay particles on $\mathrm{Al}_{2} \mathrm{O}_{3}$ and $\mathrm{TiO}_{2}$ nanoparticles transport and retention through limestone porous media. They concluded that there was a decline in the recovery with $\mathrm{Al}_{2} \mathrm{O}_{3}$ and $\mathrm{TiO}_{2}$ nanoparticles because of the presence of clay in the porous media. The position of the clay particles at the pore-throat and the morphology of the clay caused the nanoparticles to be trapped. Therefore, the mobility of $\mathrm{Al}_{2} \mathrm{O}_{3}$ and $\mathrm{TiO}_{2}$ nanoparticles through porous media is sensitive to clay type and concentration.

\section{Rheological flow behaviour of nanofluids}

The rheological flow behaviour of fluid is defined based on the relationship between the shear stress $(\tau)$ and shear rate $(\gamma)$, where the shear stress is, the tangential force applied per unit area, whereas the shear rate is the change of shear strain per unit time. Viscosity $(\mu)$ therefore, can simply be defined as the resistance to flow of liquid suspension, which is expressed as the ratio of the shear stress to shear rate. Fluid behaviour can, therefore be classified as Newtonian and non-Newtonian. For Newtonian fluids, the relationship between the shear stress and rate is linear, that is it remains constant while, that of the non-Newtonian changes with shear stress and rate.

Non-Newtonian fluids can be classified into four major group; the dilatant where the viscosity of the fluid increases when shear is applied example: quicksand, corn flour and water. The pseudoplastic in this case the more shear is applied, the fluid become less viscous example: ketchup, polymer. Rheopectic this is similar to dilatant, but the difference is when shear is applied, the viscosity increases with time, that is, it is time dependent example: we have cream, gypsum paste. Thixotropic where shear is applied, the viscosity decreases with time, which makes it also timedependent examples are: paint, cosmetic, asphalt, glue. We can therefore, conclude that non-Newtonian fluid are either time-dependent or non-time dependent.

\section{Newtonian and non-Newtonian flow behaviour of nanofluids}

The rheology flow behaviour of nanofluids can be measured by the rheometer $[103,104]$. The rheological flow behaviour of nanofluid affects the pressure drop of the nanofluid. And therefore, gives an idea of the nanofluid structure which can be used in predicting the thermal conductivity of the fluid [72].

Richmond et al. [105] studied the rheological behaviour of $\mathrm{SiO}_{2}$ and $\mathrm{TiO}_{2}$ in deionized, they observed that $\mathrm{SiO}_{2}$ alone displayed a Newtonian behaviour while, $\mathrm{SiO}_{2} / \mathrm{TiO}_{2}$ mixture 
exhibited a Bingham plastic behaviour. The addition of $\mathrm{TiO}_{2}$, increased the plastic viscosity compared to pure $\mathrm{SiO}_{2}$. $\mathrm{TiO}_{2}$ nanofluid in distilled water showed shear thinning, the intensity increased with concentration of the nanofluid, the viscosity decreases with temperature $[103,106]$. But upon exceeding a shear rate of $100 \mathrm{~s}^{-1}$, it showed a Newtonian behaviour [103]. Alphonse et al., [107] and Penkavova et al. [108] on the other hand reported a Newtonian behaviour for $\mathrm{TiO}_{2}$ with water at low shear rate and changed to shear thinning when the shear rate exceeded $100 \mathrm{~s}^{-1}$.

Tseng and $\mathrm{Wu}[109,110]$ studied the behaviour of $\mathrm{Al}_{2} \mathrm{O}_{3}$ with pure water and double distilled water in a shear range of $1-1000 \mathrm{~s}^{-1}$. For pure water, there was a transition from shear thinning to shear thickening as the shear rate exceed $100 \mathrm{~s}^{-1}$, while for double distilled water, all the suspension showed shear thinning behaviour at low shear rate and shear thickening as the shear rate exceed the critical value. Whereas the work of Prasher et al. [111] and Anoop et al. [112] on alumina/propylene glycol ( $\mathrm{PG}$ ), $\mathrm{Al}_{2} \mathrm{O}_{3} /$ water, $\mathrm{Al}_{2} \mathrm{O}_{3}$ /ethylene glycol (EG) nanoparticles, $\mathrm{CuO} / \mathrm{EG}$, they observed all the fluids exhibited Newtonian behaviour.

The work of Tseng and Chen [113, 114] was on nickel/ terpineol at shear rate ranges between 1 and $1000 \mathrm{~s}^{-1}$. All the suspension containing nickel nanofluid showed shear thinning behaviour over the entire shear rate. Whereas nickel/terpineol exhibited shear thinning behaviour for particle concentration. Silver/diethylene glycol (DEG) nanofluid exhibited a non-Newtonian (pseudoplastic) flow behaviour at a shear rate range between 1 and $200 \mathrm{~s}^{-1}$ and the viscosity increased with increase in the concentration of the fluid [115]. While, nanofluid of gold/water, the fluid exhibited Newtonian behaviour, larger-size $(50 \mathrm{~nm})$ nanofluid showed higher viscosity compared to smaller size $(10-20 \mathrm{~nm})$ nanofluid. Viscosity decreased with a rise in temperature [116].

Duan et al. [117] studied the flow behaviour of graphite nanofluid in deionized water, at a shear rate range between 1 and $100 \mathrm{~s}^{-1}$. The suspension behaviour exhibited shear thinning behaviour, viscosity increased with increase in concentration of the fluid. They also reported that the enhancement of the nanofluid held for 3-days was higher than that of the freshly prepared nanofluid. The work of Moghaddam et al. [118] was on graphene nanofluid in glycerol, at the low shear rate, the nanofluid showed shear thinning behaviour for all temperature but at high shear rate, the nanofluid behaved as Newtonian fluid and the shear thinning behaviour increased with increase in concentration.

$\mathrm{Fe}_{3} \mathrm{O}_{4}$ nanofluid in deionized water show Newtonian behaviour at low concentration and exhibited shear thinning behaviour at higher concentration $[119,120]$. But for $\mathrm{Fe}_{3} \mathrm{O}_{4}$ in polyethylene glycol (PEG), all the suspension showed shear thinning behaviour [121].

Resiga et al. [122] investigated the flow behaviour of magnetite/transformer oil nanofluid with size range of 6-7 nm and shear rate range between 1 and 1000. They concluded that all the suspensions showed Newtonian behaviour.

\section{Effects of surfactants on the rheological flow behaviour of nanofluids}

Surfactants are used to prepare stable nanofluids, to achieve a uniform particle structure throughout the suspension. It is observed by most studies that the addition of surfactant to the nanofluid changes the flow behaviour of the nanofluid [123, 124].

Yang et al. [125] work on multi-walled carbon nanotube (MWCNT)/poly-olefin oil, dispersed in polyisobutene succinimide. They concluded that the suspension with the lowest $(0.3 \%)$ and highest (8\%) dispersant concentration exhibited a shear thinning behaviour while, the intermediate (3 wt \%), exhibited a Newtonian behaviour. In their separate work on MWCNT/poly-olefin oil but with PIBSI 1000 and PIBSI 500 as the dispersant, they reported that the suspension without dispersant showed slight shear thinning behaviour at low temperature. But the shear thinning increase with increase in temperature and was very strong at $75{ }^{\circ} \mathrm{C}$. The suspension with PIBSI 1000 showed a mild shear thinning behaviour while, that of PIBSI 500 was very strong [126]. Phuoc et al. [124] in their work on MWCNT/deionized water with chitosan as the dispersant, reported that suspension with low CNT and chitosan concentration, behaved as Newtonian Fluid. While at high concentration, it exhibited shear thinning behaviour. Upon adding $0.1-0.2 \mathrm{wt} \%$ of chitosan in water increased the viscosity, while adding $0.5 \mathrm{wt} \%$ decreased the viscosity and changed the flow behaviour to non-Newtonian.

Tseng and Lin [126] investigated the rheological flow behaviour of $\mathrm{BaTio}_{3}$ /ethanol-isopropanol with anionic and cationic polymeric dispersant (KD and PS-2). They observed that the addition of the dispersant changes the flow behaviour from pseudoplastic to dilatant as the shear rate passed $800 \mathrm{~s}^{-1}$. The viscosity changed to the minimum value when the dispersant KD-6 was added. Similarly, Tseng and Li [127] used $\mathrm{BaTio}_{3} /$ distilled water with ammonium polyacrylate surfactant $\left(\mathrm{NH}_{4} \mathrm{PA}\right)$, upon adding $\mathrm{NH}_{4} \mathrm{PA}$, the suspension was close to Newtonian at the low shear rate, while it deviated from linear to dilatant flow at high shear rate. When indium tin oxide (ITO)/deionized water was used with $\mathrm{NH}_{4} \mathrm{PA}$, the viscosity reduced by about $99 \%$ as compared to the original suspension. At low shear rate the suspension behaved like a Bingham fluid and changed to shear thinning when the shear rate exceeds a critical level [128].

Phuoc and Massoudi et al. [120] studied the rheological flow behaviour of $\mathrm{Fe}_{2} \mathrm{O}_{3}$ /deionized nanofluid with polyvinylpyrrolidone (PVP) and poly-ethylene oxide (PEO) surfactant. They reported that, the PEO and PVP exhibited a Newtonian behaviour at low concentration $(0.2 \mathrm{wt} \%)$ and 
exhibited shear thinning at higher concentration of the nanoparticle.

\section{Effect of polymer on the rheological flow behaviour of nanofluids}

In polymer flooding activity, the essence of adding polymer to brine is to increase the viscosity for better sweep efficiency [4]. Studies have shown that adding nanofluids to polymer solution enhances the viscosity of the solution [37]. Adding nanofluids to polymer increases the network and chain of the polymer, which in turn increases the viscosity of the nanofluid. Therefore, nanofluid induced polymer has higher viscosity than polymer solution alone. Figure 9 is the oil recovery performance of injected polymer and nanoparticle-induced polymer fluid.

Nanofluids are used to improve the mechanical, electrical and barrier properties of polymers, there are used as thickening agent for low viscosity Newtonian fluid. It is therefore, desirable to know the effect of these nanoparticles to the rheology of the nanofluid and the approach needed to model the rheology of the system. The rheology also provides a means to determine the degree of exfoliation of the nanofluid in a polymer melt, the particles are therefore, sensitive to structure, shape and particle size [129].

The addition of particles to a flowing liquid with complementary disturbance of the flow lines, can result in the simplest flow becoming complex. The flow pattern changes where there is increase and spatial variation of the shear rate in the continuous phase and transient behaviour of the liquid element. The Van der Waals forces between particles encourages agglomeration and influence the flow properties from the increase in flow phase value. Aggregation of

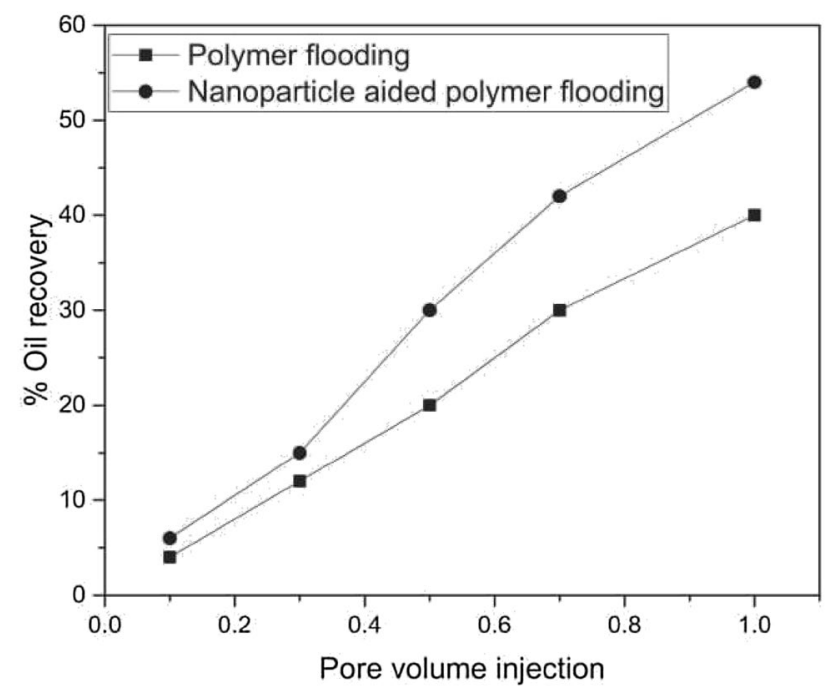

Fig. 9 Oil recovery performance of injected polymer and nanoparticle-induced polymer fluid [37] nanoparticles increases the distortion of flow lines and have effects on the rheological properties such as viscosity and normal stress [37, 129].

At equal concentration, well-dispersed nanofluid exhibit different rheological behaviour compared to agglomerated counterparts. The complications therefore, invalidate any assumptions governing macroscopic homogeneity for the application of complex equation over the homogenous phase. To account for additional time derivatives, spatial as well as particle-particle and particle-matrix molecular interaction, factors such as particle size, porous media such as $\mathrm{pH}$, polarity and inherent functionality also dictates the flow in porous media by regulating aggregation and flocculation. The degree of slip at the wall of the porous media and the amount of phase separation is influenced by the plate roughness or vane geometry. Viscosity as a function of concentration has been modelled by several authors [130-135]:

$\eta_{s p}=\eta_{r}-1=\eta / \eta_{s}-1=2.5 \infty$,

$\frac{\eta}{\eta_{s}}=1+2.5 \infty+6.2 \infty^{2}$,

$\frac{\eta}{\eta_{s}}=(1-k \emptyset)^{x}$

$\frac{\eta}{\eta_{s}}=\left(\frac{1}{1-\emptyset \emptyset_{m}}\right)^{\emptyset_{m}[\eta]}$

whereas $\varnothing$ is the packing volume fraction, $k$ is the constant of integration and $\eta$ is the intrinsic viscosity.

Maghzi et al. [37] investigated the effect of silica nanofluid on the rheological behaviour of polyacrylamide to enhanced oil production. They concluded that preliminary study showed that Nano solution showed pseudoplastic behaviour and had a good match with the power law model. But the rheological behaviour of the polyacrylamide showed a slight deviation from the power law model at medium shear rate and the deviation increased at higher shear rate. But for both fluids, there was minimum deviation. Addition of nanofluid improved the pseudoplasticity and increased viscosity for all the test.

Cheraghian and Khalilinezhad [136] studied the effect of nanoclay on the rheological behaviour of polymeric solution. They reported that there is a lower and upper limit for effective viscosity of the polymer solution in porous media. The ultimate recovery increased by $5 \%$ compared to polymer flooding alone.

Cheraghian [137] applied nano-fumed silica to increase the viscosity of polymer in heavy oil flooding. They concluded that, the viscosity of the nano suspension increased with nanofluid weight fraction. More nanoparticles had direct effect on the fluid shear stress and the ultimate 
recovery by nanosilica increased by $8.3 \%$ compared to polymer flooding alone. Similarly, the effect of $\mathrm{TiO}_{2}$ nanofluid on heavy oil recovery during polymer flooding was investigated. They concluded that for polymer flooding to be effective, the concentration of the nanofluid should be above a threshold value, the threshold value for titanium dioxide was $2.3 \mathrm{wt} \%$. The ultimate oil recovery by nanofluid flooding increased by $3.9 \%$ compared to polymer flooding alone [138].

\section{Mathematical modelling of nanoparticle flow behaviour}

The flow behaviour of nanoparticles in porous media can be govern by the following assumptions; the porous media is heterogenous, the flow is one-dimensional under isothermal condition, the rock and fluid are incompressible, the oil and water are governed by the Darcy's law and as such gravitational force is neglected. Oil and water are Newtonian fluids therefore, the viscosity and density are kept constant, the nanoparticles are discretized into $\mathrm{n}$ size intervals.

The continuity equation of oil ( $o$ ) and water $(w)$ are governed by the following equations:

$\frac{\partial}{\partial l}\left(\emptyset s_{l}\right)-\frac{\partial}{\partial x}\left(\frac{k_{l} \partial p_{l}}{\mu_{l} \partial x}\right)=o ; l=o, w$,

$P_{C}=P_{o}-P_{w}=\frac{a+b S_{w}}{1+c S_{w}}$,

whereas $x$ is the distance from the inlet of the porous media, $l$ is the line, $\varnothing$ is the porosity, $s_{l}$ is the saturation, $\mu_{l}$ is viscosity, $p_{l}$ is pressure of the phase $l$ and $k_{1}(=k r l)$ is the effective permeability of phase 1. Whereas Eq. (7) is the expression for capillary force, where $a, b, \mathrm{c}$ are empirical parameters and $S_{\mathrm{w}}$ is water saturation.

$\mathrm{Ju}$ and Fan [33] used a mathematical model to describe nanoparticles transport in a two-phase flow. The water phase permeabilities increased from 1.6 to 2.1 of the original values, but there was a decrease in absolute permeabilities because of the adsorption of the nanoparticles at the pore throat of the porous media. The hybrid computational approach that combines the lattice Boltzmann model for binary fluid with Brownian dynamic model for nanoparticles was used to capture the interaction among fluids, nanoparticles and pore wall. Ma et al. [139] demonstrated that nanoparticles can alter the IFT between two fluids and contact angle at the pore walls which affects the dynamics of the capillary fillings. But Cleary et al. [140] confirmed the Darcy's law for drift velocities in a saturated medium. Whereas a non-linear behaviour was observed for higher values using the smoothed particle hydrodynamics (SPH) when they demonstrated that the flow through a porous structure can be treated at a mesoscopic level similar to that used in lattice gas and lattice Boltzmann simulation. It also showed that complex physics such as multiphase flow, realistic equation of state, heat transfer and curing can be included in a rigorous manner. Furthermore, complex geometry can be handled in a simple manner and the extension from twodimensional flow is straight forward. In the absence of gravitational force, El-Amin et al. [141] used a highly non-linear parabolic partial differential equation to numerically solve an efficient algorithm. They developed a mathematical model to describe the magnetic nanoparticles-water suspension that imbibes into water-oil two phase flow in a porous media under magnetic field effect. The saturation of nanoparticles water suspension increases, while the nanoparticle concentration decreases slightly under the effect of the magnetic field as the deposited nanoparticles concentration increases. This was demonstrated by a set of numerical exercise of hypothetical cases to show how an external magnetic field can influence the transport of nanoparticles in a two-phase system in a porous media [142]. The water-nanoparticles suspension was treated as a miscible mixture, whereas it is immiscible with the oil phase. They concluded that the magnetic source location has a significant influence on the physical variables of the model. Based on the flow direction and the location of the magnet, the magnetic field can assist or oppose the flow of this two-phase system. The concentration of the nanoparticles is observed to decrease slightly as a result of slight increase in deposition of nanoparticles. The magnet can assist the flow of the ferrofluid suspension when placed next to the inflow/outflow boundary. The concentration of the nanoparticles seems to increase under the effect of magnetic field as the concentration of the nanoparticles deposited decreases [141].

\section{Modification of nanoparticles}

The surface chemistry of a material determines its filtration, adsorption and the rheological behaviour of the material in porous media. Therefore, proper surface modification can control particle properties which can lead to proper emulsification, reduced particle retention, wettability alteration and stabilization of foam. A well-designed surface modified nanoparticle can change particle hydrophobicity and thus alleviate particle retention on the rock surface [46]. As careful control of emulsification and demulsification leads to delivery of nanoparticles to targeted areas in the formation.

The interfacial interaction between two phases present in a hybrid solution is one of the decisive factors affecting properties of nanoparticles, a good dispersion can be achieved by surface modification of the nanoparticles with active functional groups to enhance the compatibility between the nanoparticles with surfactant or polymer thereby, optimizing the efficiency of the process. 
The surface modification of nanoparticles can be realized by chemical or physical methods.

1. Chemical methods: the use of chemical methods involve modification with either modifier agents or by grafting polymers. The most commonly used chemical modifying agents are the silane coupling agents which possess hydrolysable and organofunctional ends. The general structure of the coupling agents can be represented as $\mathrm{RSiX}_{3}$, where the $\mathrm{X}$ represents the hydrolysable groups, which are typically chloro, ethoxy, or methoxy groups. Whereas the $\mathrm{R}$ is an organic group of different functionalities chosen to meet the requirements of the polymer. The functional group $\mathrm{X}$ reacts with the hydroxyl groups on the surface of the nanoparticles, while the alkyl chain reacts with the polymer matrix. In this way, the hydrophilic surface of nanoparticles is converted into hydrophobic [143]. Grafting of polymer is also an effective method used to increases the hydrophobicity of particles. Surface modification by grafting is achieved through two main approaches;

(i) 'Grafting to' method: this is the covalent attachment of end-functionalized polymers to the surface of the nanoparticles [144].

(ii) 'Grafting from' method: its the in situ monomer polymerization with monomer growth of polymer chain from an immobilized initiator [144].
The advantages of grafting polymerization include;

(a) Grafting of polymers can improve the interfacial interaction between the grafting polymer on the nanoparticles and the matrix polymer. This can be achieved by molecular entanglement of the polymer to the nanoparticles.

(b) Grafted polymerization can also increase the hydrophobicity of nanoparticles. Which can be useful as fillers and for matrix miscibility.

(c) It provides flexible structural properties between the nanocomposites. This can be achieved by changing the species of the grafting monomers and the grafting conditions. This is because, different grafting polymers might have different interfacial characteristics.

Guo et al. [145] functionalized $\mathrm{SiO}_{2}$ nanoparticle with a silane compound, 3-methacryloxypropyltrimethoxysilane (MPS) (Fig. 10) and found that the grafting ratio of MPS on the surface of nanosilica increased with MPS content.

Sabzi et al. [146] carried out surface modification of $\mathrm{TiO}_{2}$ nanoparticles with amino propyltrimethoxysilane (APS) and investigated its effect on polyurethane composite coating. Iijima et al. [147] tuned the stability of $\mathrm{TiO}_{2}$ nanoparticles in various solvents by mixed silane alkoxides and obtained a well dispersed $\mathrm{TiO}_{2}$ in acidic aqueous solution, while Ukaji et al. [148] used 3-aminopropyltriethoxysilane (APTES) and $n$-propyltriethoxysilane (PTES) to suppress the photo-catalytic activity of fine $\mathrm{TiO}_{2}$ particles as inorganic ultraviolet filter. All the researchers observed an improvement of the
Fig. 10 Modification of a nanoparticle with MPS (silane coupling agent) [145]

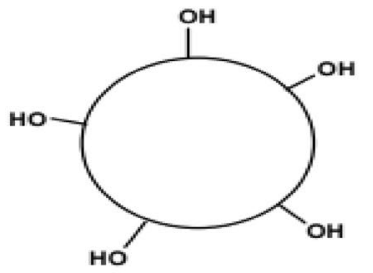

nanoparticle

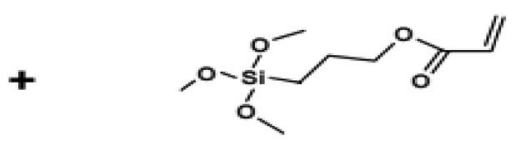

3-methacryloxypropyl trimethoxysilane

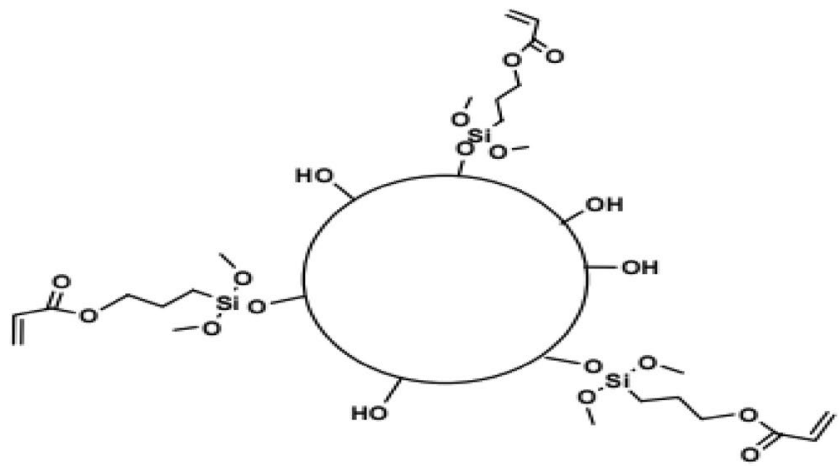


properties of nanoparticles used after the surface modification process.

2. Physical method: the surface modification of nanoparticles based on physical interaction is usually implemented by adsorption of surfactants or macromolecules onto the surface of the nanoparticles. The principle of surfactant treatment is the preferential adsorption of a polar group of a surfactant to the surface of the nanoparticles by electrostatic interaction. The surfactant used for surface modification of nanoparticles are the cationic and anionic surfactants [138]. The hydrophilic head of the surfactant reduces the interaction between the nanoparticles within agglomerates by reducing the physical interaction while, the hydrophobic tail easily incorporates them into the polymer matrix (Fig. 11). Thereby, improving their efficiency [143]. For instance, silica was treated with CTAB to improve the chemical interaction between the $\mathrm{SiO}_{2}$ and the polymer [149]. Nanoslica was also modified with oleic acid, the oleic acid was bonded to the silica surface with a single hydrogen bond [150].

Adsorption of polymer can also provide surface hydrophobicity of silica nanoparticles. This was demonstrated by Reculusa et al. [151] when they modified the surface of silica nanoparticles by adsorption of an oxyethylene based macromonomers. Hydrogen bond with the silanol functions present on the surface of the silica was formed. This was possible due to the hydrophilic nature of the monomers due to the presence of ethylene oxide group. On the other hand, the methacrylate group which contains a polymerizable group for the syrene reaction might also be responsible.

Lai et al. [152] modified $\mathrm{SiO}_{2}$ nanoparticles with stearic acid to improve their dispersion and the adhesion between the filler and polymer matrix. They reported that the modified nano- $\mathrm{SiO}_{2}$ viewed under scanning electron microscope was seen to disperse uniformly in poly (ether ether ketone) than the unmodified counterpart. Tang et al. [153] modified

Anionic surfactant sodium dodecyl sulphate $\left(\mathrm{C}_{12} \mathrm{H}_{25} \mathrm{SO}_{4}{ }^{-} \mathrm{Na}^{+}\right)$

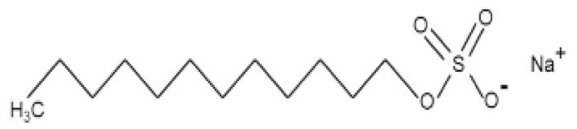

Cationic surfactant dodecyltrimethyl ammonium bromide $\left[\mathrm{C}_{12} \mathrm{H}_{25} \mathrm{~N}\left(\mathrm{CH}_{3}\right)_{3}{ }^{+} \mathrm{Br}\right]$

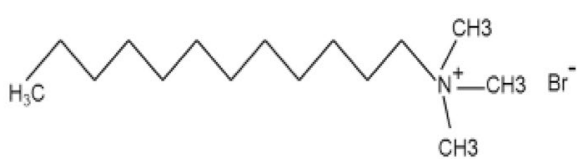

Fig. 11 Commonly used surfactants for functionalisation of nanoparticles [143] nano-sized $\mathrm{SiO}_{2}$ with oleic acid (OA) and the surface-modified silica nanoparticles $\left(\mathrm{SiO}_{2}-\mathrm{OA}\right)$ were dispersed in poly (amic acid). They observed that the surface modification of the nanoparticles caused an enhanced dynamic mechanical properties and thermal stability of the polymer.

Behzadi and Mohammadi et al. [154] modified silica nanoparticles with polyethylene glycol as a hydrophobic agent and propyl chain as the hydrophilic agent. The oil water IFT was decreased by $50 \%$ and it modified the oil wetted surface from strongly oil wet to water-wet. The increase in nanoparticle concentration increased the surface activity as the functional nanoparticles can greatly improve the performance of the biochemical analysis. Which can accelerate the signal transduction, enhance signal intensity and enable the radiance of the signal due to the unique properties of the nanoparticles. The pre-level investigation experiment with the surface modified silica nanoparticles reveals that hydrophilic and environmental friendly silica nanoparticles can also modify micro model wettability.

The surface chemistry does not only affect the quality of the nanoparticles in terms of stability, mono-dispersity and biocompatibility but can also prove that the functional groups of $-\mathrm{COO}^{-},-\mathrm{NH}_{3}^{+},-\mathrm{CHO}$ or the charges on the nanoparticles can be exploited for ligand exchange. Yang et al. [155] modified ALOOH nanoparticles with partial hydrophobic, positive and slightly negative charged. Small aggregate adsorbs to the surface and form compatibility network in the foam film resulting in a stable foam. The surface chemistry is therefore, a vital tool for surface medication as it dictates the sensitivity and mediation of the specific nanoparticles assay, which is vital to the orientation of the functional ligand on the nanoparticles [155]. Taber et al. [156] determined the best nanohybrid that can be used as a pickering emulsion for EOR. They prepared different carbon structure (single-walled carbon nanotube, SWCNT and multiwalled carbon nanotube, MWCNT) nanohybrid with $\mathrm{SiO}_{2}$ nanoparticles with different weight-percent using sol-gel method. The results showed that nanofluid could significantly change the wettability of the carbonate rock from oil to water wet and decreases the IFT. Pickering emulsion have a good stability at $0.1,1 \%$ salinity, at moderate and high temperature $\left(25\right.$ and $\left.90{ }^{\circ} \mathrm{C}\right)$, neutral and alkaline $(7,10) \mathrm{pH}$, which is suitable for oil reservoir condition. Therefore, $70 \%$ $\mathrm{NWCNT} / \mathrm{SiO}_{2}$ nanohybrid pickering emulsion can be used for EOR.

\section{Characterization methods for evaluating the influence of nanoparticles in EOR}

Nanoparticles can be characterised based on their surface morphology, particle size and surface charge. The surface morphology, particle size and shape are determined by the electron microscopy technique. Whereas the physical 
stability and dispersibility of the nanoparticles are affected by the surface charge of the nanoparticles [157].

(a) Surface morphology: the electron microscopy technique is usually used to determine the surface morphology with a direct visualization of the nanoparticles. The scanning electron microscopy (SEM) and the transmission electron microscope (TEM) are used for this purpose. The SEM can provide the morphology and size analysis of the nanoparticles. But its limitation is insufficient information on the size distribution and the true population average [158]. The difficulty in studying the structure of nanoparticles is due to their small size, which can hinder the use of traditional methods in measuring their physical properties. TEM technique can provide imaging, diffraction and spectroscopic information of the nanoparticles. The advantage of TEM is that, it can provide the shape, size, defect, surface structure, crystals, electronic state and composition in nanometre-size region of thin film, nanoparticles and nanomaterial system [157].

(b) Particle size: particle size is a physical property that gives the basic information of the nanoparticles. It determines the distribution and retention of the nanoparticles in the target area [159]. Dynamic light scattering (DLS) is used to determine the size of the nanoparticles. It measures the Brownian motion of the nanoparticles in suspension and relates it to velocity (Known as the translational diffusion coefficient) to the size of the nanoparticle. According to the Stoke's-Einstein equation [159] DLS is fast and can provides a simple estimate of the particles size. But the limitation of DLS is that, it is poor in analysing multimodal particle size distribution [160]. Nanoparticle tracking analysis (NTA) is another imaging technique. It can track a single particle based on the fluorescence microscopy atomic image analysis. The size is determined from the average displacement of the nanoparticle undergoing Brownian motion at a time [161]. The advantage of this method is that, it can track a single nanoparticle and provides a high resolution for the sample and aggregation.

(c) Surface charge: the surface charge influences the interaction of the nanoparticles with the environment. It also, determine the intensity and electrostatic interaction with bioactive compound [157]. The stability of colloidal material is usually analysed with the zeta potential of the nanoparticles. It is an indirect measure of the surface charge, it is useful in determining the stability of the nanoparticles, to avoid aggregation of the nanoparticles. It can also be used to evaluate surface hydrophobicity and nature of the nanoparticles [162].

\section{The efficiency of different nanoparticles during oil displacement test}

The interest of nanotechnology in the oil and gas industry is increasing by the day, silica nanoparticles are the most widely tested and has shown good EOR application. But recently, studies have been carried out on aluminium oxide, titanium oxide, iron oxide, and magnesium oxide, when combined they have yielded better result. In the near future, the oil and gas industry will benefit tremendously from nanotechnology.

Adding nanoparticles to fluid greatly increases the mobility of trapped oil, reduces interfacial tension, changes the properties of fluid, wettability alteration [163]. Although, the exact mechanism for oil displacement using nanoparticles is still not clear [164, 165], nanotechnology has been seen as the alternative to recover the remaining oil trapped in the reservoir $[166,167]$.

Maghzi et al. [37] monitored the wettability alteration using silica nanoparticles during water flooding of heavy oil, they experimented with micromodel and reported a $26 \%$ incremental oil recovery using silica nanoparticles.

Maghzi et al. [37] study using silica nanoparticles with polyacrylamide solution, with glass micromodel had a $10 \%$ additional oil recovery.

Joonaki and Ghanaatian [44] in their study used iron oxide, aluminium oxide, and silicon oxide treated by silane, using sand pack as the porous media, reported that the ultimate recovery was $92.5 \%$ with iron oxide, $88.6 \%$ with aluminium, and $95.3 \%$ with silica oxide.

Charaghian [168] also using a glass micromodel but with sodium bentonite nanoclay with a size of $50 \mathrm{~nm}$ was able to recover $60.6 \%$ of the OOIP. Also, in another of his work using nanoclay and polymer with sandpack as the porous media to recovery heavy oil, the additional recovery this time was $5.8 \%$.

Manan et al. [169] used $\mathrm{SiO}_{2}$, aluminium oxide, copper oxide and titanium dioxide as a stabilizing agent in carbon dioxide foam flooding, using sand pack as the porous media. The additional recovery reported was $14 \%$ for alumina, $11 \%$ for silica while, titanium and copper recovered $5 \%$ each.

Nazari et al. [36] in his work on wettability alteration of carbonate rocks used $\mathrm{ZrO}_{2}, \mathrm{TiO}_{2}, \mathrm{MgO}, \mathrm{Al}_{2} \mathrm{O}_{3}, \mathrm{CeO}_{2}$, $\mathrm{CNT}$, where all used for contact angle measurement while, $\mathrm{CaCO}_{3}$ and $\mathrm{SiO}_{2}$ were used for core flooding. The result showed 8-9\% additional recovery.

Moradi et al. [170] also used silicon dioxide nanoparticle on a carbonate porous media and they reported a $72-79 \%$ recovery of the original oil in place. Sharma et al. [17] also worked on silica nanoparticles but with Berea sandstone, the nanoparticle was used as a stabilizer 
for surfactant and polymer. And the cumulative oil recovery was $60 \%$. The work of El-Diasty [171] also with silica nanoparticle on sandstone media, reported a 35-50\% recovery of the OOIP during breakthrough point. Chen et al. [172] used carbonaceous nanoparticles MWCNT and carbon black (CB) injected with surfactant blend. They reported a fast and high recovery of $42.7 \%$ compared to surfactant alone.

Singh and Mohanty [90] used aluminium coated silica, with Berea sandstone as the porous media, the cumulative oil recovery reported was 70-75\%. Alomair et al. [173] in their work also using Berea sandstone as the porous media but with aluminium oxide and nickel oxide, silicon oxide, titanium oxide, observed a $6 \%$ incremental oil recovery for silicon oxide and aluminium oxide, 1-3\% for nickel oxide and titanium oxide. Ragab and Hannora [58] also worked with silica and aluminium nanoparticles, with Berea sandstone as the porous media, they reported a $7 \%$ additional recovery.

Bayat and Junin [9] in their work on nanoparticle transport through porous media, using limestone as the porous media and $\mathrm{Al}_{2} \mathrm{O}_{3}, \mathrm{TiO}_{2}$ and $\mathrm{SiO}_{2}$ nanoparticles, reported that a tremendous increase in recovery of $52.6 \%$ for aluminium, $50.9 \%$ for titanium and $48.7 \%$ for silica as compared to the original $47.3 \%$ of water flooding.

Ogolo et al. [8] using sandstone as the porous media work on eight different nanoparticles namely; aluminium oxide, magnesium oxide, iron oxide, nickel oxide, zinc oxide, zirconium oxide, tin oxide, and silane treated silicon oxide. They reported that iron oxide gave the highest recovery, while magnesium was the least. The total recovery for the nanoparticles is as follows: aluminium $26.7 \%$, magnesium $18.3 \%$, iron $30 \%$, nickel $25 \%$, zinc $29.2 \%$, zirconium $27.5 \%$, Tin $25 \%$, and silane treated silicon $27.5 \%$.

Onyekonwu and Ogolo [7] studied the wettability alteration of three different polysilicon nanoparticles to enhance oil recovery, the nanoparticles used were lipophobic and hydrophobic (LHPN), hydrophobic and lipophobic (HLPN) and neutrally wet (NWPN). They reported that HLPN and NWPN are good agent for enhanced oil recovery with a total recovery between 42.95 and $53.38 \%$ for LHPN, 70.62-86.92\% for NWPN and 70.0-93.13\% for HLPN.

Mohammadi et al. [21] investigated the effect of $\gamma-\mathrm{Al}_{2} \mathrm{O}_{3}$ on the wettability alteration of one Iranian carbonate reservoir, they observed a maximum change in contact angle and the oil recovery increased by $11.25 \%$.

Wan Sulaiman et al. [35] they used silica nanoparticle in carbonate rock to alter the wettability of the rock, and to test the efficiency of silica nanoparticle in enhancing oil recovery in high salinity, they reported a $65.5 \%$ recovery of the OOIP.

Cheraghian [137] focused on the role of $\mathrm{TiO}_{2}$ nanoparticle on the viscosity of polymer, his results showed that polymer with high viscosity can improve oil recovery, the displacement test indicate a $4 \%$ increase in oil recovery. Cheraghian [138] this time, focused on silica nanoparticle effect on the viscosity of polymer and its improvement in recovering heavy oil. The result indicated that nanoparticles with polymer at higher viscosity can improve oil recovery, the displacement test for silica nanoparticle was $8.3 \%$ increase in recovery.

Jafarnezhad et al. [174] applied $\mathrm{SnO}_{2}$ nanoparticles to increase the efficiency of water flooding in heavy oil using carbonate core plug. The nanoparticles altered the wettability from oil-wet to water-wet and reduced the IFT which led to the increase in the recovery factor from 39 to $61 \%$ at low concentration of the nanoparticles. Azarshin et al. [143] modified the surface of the silicon nanoparticles to make them more effective for EOR purposes. They found out that the amine-functionalized silica nanoparticles are significantly more effective than the typical nanoparticles when the core flood test recovered $18 \%$ increase in total recovery compared to the typical nanoparticles. But Zallaghi et al. [176] reported an increase from 4.87 to $11.7 \%$ in sandstone core when the surface of silica nanoparticles was modified. While Youssif et al. [177] concluded that silicon nanoparticle is environmentally compatible with sandstone rocks. Recovery increased by $13.28 \%$ with increase in the concentration of nanoparticles and that injecting silica at low concentration rate will decrease the permeability impairment. Whereas high concentration will increase the impairment but, will increase the recovery to a certain extent.

Nwidee et al. [32] investigated the influence of $\mathrm{ZrO}_{2}$ and $\mathrm{NiO}$ nanoparticles on the wetting preference of fractured oilwet limestone formation. Both nanoparticles demonstrated similar behavior at the same particle concentration but the $\mathrm{ZrO}_{2}$ demonstrated a better efficiency by altering oil-wet to water-wet condition while, $\mathrm{NiO}$ changed oil-wet to intermediate condition. They concluded that $\mathrm{ZrO}_{2}$ is very efficient in terms of inducing strong water-wettability and has high potential as an EOR agent.

\section{Field application of nanoparticles in EOR}

Nanoparticles was used to improve the mobility and alter the wettability of two Columbian heavy oil fields. Two field trials were performed in Castilla and Chichimene fields [6]. In Castilla 200 and $150 \mathrm{bbl}$ of nanofluid were injected into wells CN154 and CN174, respectively. The oil rate increased by 270 bpd in CNI54 and 280 bpd in CN174. Whereas in Chichimene 86 and $107 \mathrm{bbl}$ of nanofluid were injected into wells CHSW26 and CH39, respectively. Oil rate increased by 310 bopd in CHSW26 and 87 bopd in CH39. It was observed that the oil viscosity reduced, and the mobility ratio was increased for both fields. About $98 \%$ viscosity was observed 
for Chichimene field in the first 9 days whereas $47 \%$ reduction in viscosity was observed for Castilla in the first 30 days [6]. The nanofluid was pumped into the formation just once and the improvement in oil mobility was still the same for 269 days. Indicating the efficiency and economical nature of the nanofluid. The residual concentration of the nanoparticle after 269 days was $56 \mathrm{ppm}$, indicating that the long life of the nanofluid. Also, $11 \%$ reduction in BSW shows that the formation has been altered to a strong water wet system. The project was very economical as the capital invested was recovered within 4 months.

\section{Challenges of nanoparticles applications}

\section{Processing and manufacture}

There is little or no doubt that nanoparticles have tremendous market potentials, but as a replacement for current EOR chemicals and in the creation of new market through their outstanding properties. But the challenge is the processing and manufacture technology in terms of quantity and commercialization is the greatest challenge. The dispersion of nanoparticles or the chemical compatibility of the nanoparticle with the material is important. The homogenous dispersion of the nanoparticles in polymer is very difficult due to the strong tendency of particles to agglomerate $[178,179]$. Scale up is needed to produce large quantities of nanomaterials for manufacturing purposes, there is need for characterization method, tools, instrumentation as well as affordable infrastructure, and the education of scientist and engineers in academics and industry. Molecular dynamics simulation and theoretical analysis are based on assumption that may not be feasible in real life situation [180].

\section{Environmental challenges}

There are general views that nanoscale particles may have negative health and environmental hazards, since most of them are metals or their oxides [181, 182]. Although most of them are introduced into the body for detecting disease and infections, imaging and treatments, there is growing concern about their toxicity. The properties of carbon nanoparticles may also lead to health hazard [183]. Because the size of the nanoparticles is comparable to human cells and large protein with the result that the regular human immune system may not work against them [184]. Nanoparticles can also seep into under underground water to affect the aquifer, which is a serious environmental problem.

\section{Future direction}

Nanotechnology in EOR is still at the laboratory and field trial stage, where there is an attempt to understand the mechanism of its adsorption onto rock surface during recovery, because different rock has different affinity to adsorbed nanoparticles. The mechanism of nanoparticle retention and entrapment needs to be understood, they are in need for size control and the right concentration of nanoparticles for flooding.

Considering the number of publication and good result obtained from laboratory, nanoparticles are potential future candidate for EOR, but this has not reflected on its application in the field. Several challenges still exist that need to be addressed, such as the stability of the nanoparticles at harsh conditions, to solve these problems, copolymerization, nanoparticle coating and surface modification of these nanoparticles should be implemented.

The cost of nanoparticles is another limiting factor hindering field application. There is need to develop tailor-made nanoparticles that are cost-effective from local material such as natural starch and cellulose. The choice of these materials is due to their rigid chemical structure which can withstand harsh reservoir condition and they are the most abundant natural product in nature.

\section{Conclusions}

1. The main aim of this research is to bring to light the mechanism affecting the flow of nanoparticles in porous media as it relates to EOR.

2. Nanoparticle in CEOR can alter the wettability of the reservoir rock from oil-wet to water-wet, it can also lower the interfacial tension between the oil and water interface. Nanoparticles are found to be effective in stabilizing of emulsion, foam and can also stabilize oil front.

3. Gravitational and capillary forces are responsible for the shift in wettability from oil-wet to water-wet.

4. The flow of nanoparticles in porous media was described laying emphasis on the physical aspect of the flow, the microscopic rheological behaviour and the adsorption of the nanoparticles in porous media.

5. It was observed that nanoparticles exhibit Newtonian behaviour at low shear rate and non-Newtonian behaviour at high shear rate.

6. The dominant mechanism of foam flow process were lamellae division and bubble to multiple lamellae division. 
7. In a water-wet system, the dominant mechanism of the flow process and residual oil mobilization are lamellae division and emulsification, respectively, while in an oilwet system, the generation of pre-spinning continuous gas foam was the dominant mechanism.

8. Experimental and field trial results indicate that nanoparticles can recover additional oil from the reservoir.

9. There are some challenges facing nanoparticle application such as processing, manufacture and environmental issues.

Acknowledgements The authors would like to thank the Ministry of Higher Education (MOHE), Malaysia, and Universiti Teknologi Malaysia (UTM), for supporting this research through Research Management Grant Vot. no. Q. J30000.2546.14H50.

Open Access This article is distributed under the terms of the Creative Commons Attribution 4.0 International License (http://creativeco mmons.org/licenses/by/4.0/), which permits unrestricted use, distribution, and reproduction in any medium, provided you give appropriate credit to the original author(s) and the source, provide a link to the Creative Commons license, and indicate if changes were made.

\section{References}

1. Abbas, A.H., Wan Sulaiman, W.R., Zaidi, J.M., Agi, A.A.: Anionic surfactant adsorption: insight for enhanced oil recovery. Recent. Adv. Petrochem. Sci. 1, 5 (2017)

2. Kaul, A., Chauhan, R.P.: Effect of gamma irradiation on electrical and structural properties of $\mathrm{Zn}$ nanowires. Radiat. Phys. Chem. 100, 59-64 (2014)

3. Bera, A., Belhaj, H.: Application of nanotechnology by means of nanoparticles and nanodispersions in oil recovery-a comprehensive review. J. Nat. Gas. Sci. Eng. 34, 1284-1309 (2016)

4. Agi, A., Junin, R., Gbonhinbor, J., Onyekonwu, M.: Natural polymer flow behaviour in porous media for enhanced oil recovery applications: a review. J. Pet. Explor. Prod. Technol. (2018). https ://doi.org/10.1007/s13202-018-0434-7

5. Mahmoud, O., Nasr -El-Din, H.A., Vryzas, Z., Kelessidis, V.C.: Nanoparticle-based drilling fluids for minimizing formation damage in HP/HT applications. Paper SPE-178949-MS. In: Presented at SPE international conference and exhibition on formation damage control, Lafayette, Louisiana, USA, 24-26 February (2016)

6. Zabala, R., Franco, C., Fortes, C.: Application of nanofluid for improving oil mobility in heavy oil and extra-heavy oil: a field test. paper SPE-179677-MS, presented at the SPE improved oil recovery conference, held in Tulsa, Oklahoma, USA, 11-13 April (2016)

7. Onyekonwu, M.O., Ogolo, N.: Investigating the use of nanoparticles in enhancing oil recovery. 34th annual SPE international conference and exhibition held in Tinapa, p. 14. SPE-140744 (2010)

8. Ogolo, N., Olafuyi, O., Onyekonwu, M.: Enhanced oil recovery using nanoparticles. Saudi Arabia Section Technical Symposium and Exhibition, p. 9 (2012)

9. Bayat, A.E., Radzuan, J.: Transportation of metal oxide nanoparticles through various porous media for enhanced oil recovery. In: Paper SPE-176365-MS, presented at the SPE/IATMI Asia Pacific Oil and Gas Conference and Exhibition, held in Nusa Dua, Bali, Indonesia, 20-22 October (2015)
10. Sun, X., Zhang, Y., Chen, G., Gai, G.: Application of nanoparticles in enhanced oil recovery: a critical review of recent progress. Energies 10(3), 345 (2017)

11. El-Diasty, A., Ragab, A.: Application of nanotechnology in the oil and gas industry: latest trend worldwide and future challenges in Egypt. Paper SPE 164716-MS, presented at the North Africa Technical Conference and Exhibition held in Cairo, Egypt, 15-17 April (2013)

12. Mandal, A., Bera, A., Ojha, K., Kumar, T.: Characterisation of surfactant stabilized nanoemulsion and its use in enhanced oil recovery. In Proceedings of the SPE international oil field nanotechnology conference and exhibition, Noordwijk, The Netherlands, 12-14 June (2012)

13. Binks, B.P., Philip, J., Rodrigues, J.A.: Inversion of silica stabilized emulsion induced by particle concentration. Langmuir 21, 3296-3302 (2005)

14. Hashemi, R., Nassar, N.N., Almao, P.P.: Nanoparticle technology for heavy oil in situ upgrading and recovery enhancement: opportunities and challenges. Appl. Energy 133, 374-387 (2014)

15. Kong, X., Ohadi, M.: Application of micro and nano technologies in the oil and gas industry-overview of recent progress. Paper SPE-138241-MS, presented at Abu Dhabi International Petroleum Exhibition and Conference, 1-4 November (2010)

16. Hadi, S., Miller, C., Wong, M., Tour, J., Verduzco, R.: Polymer coated nanoparticles for enhanced oil recovery. J. Appl. Polym. Sci. 131, 15 (2014)

17. Sharma, T., Kumar, G.S., Sangwai, J.S.: Comparative effectiveness of production performance of pickering emulsion stabilized by nanoparticles-surfactants-polymer over surfactant-polymer (SP) for enhanced oil recovery for Brownfield reservoir. J. Pet. Sci. Eng. 129, 221-232 (2015)

18. Bera, A., Mandal, A., Kumar, T.: The effect of rock-crude-oilfluid interaction on wettability alteration of oil-wet sandstone in the presence of surfactants. Pet. Sci. Tech. 33(5), 542-549 (2015)

19. Wason, D.T., Nikolov, A.D.: Spreading of nanofluids on solids. Nature 423, 156-159 (2003)

20. Giraldo, J., Benjumea, P., Lopera, S., Cortes, F., Ruiz, M.: Wettability alteration of sandstone cores by alumina based nanafluids. Enery Fuels 27, 3659-3665 (2013)

21. Mohammadi, M., Moghadasi, J., Naseri, S.: An experimental investigation of wettability alteration in carbonate reservoir using $\gamma-\mathrm{Al}_{2} \mathrm{O}_{3}$. Nanoparticles 3(2), 18-26 (2014)

22. Hendraningrat, L., Li, S., Torsaeter, O.: Effect of some parameters influencing oil recovery process using silica nanoparticles: an experimental investigation. In Proceedings of SPE reservoir characterization and simulation conference and exhibition, Abu Dhabi, UAE, 16-18 September (2013)

23. Mohammed, M., Babadagli, T.: Wettability alteration: a comparative review of materials/methods and testing the selected ones on heavy-oil containing oil-wet system. Adv. Colloid Interface Sci. 220, 54-77 (2015)

24. Moghadam, A.M., Salehi, M.B.: Enhancing hydrocarbon productivity via wettability alteration: a review on the application of nanoparticles. Rev. Chem. Eng. (2018). https://doi.org/10.1515/ revce-2017-0105

25. Buckley, J.S., Liu, Y., Monsterleet, S.: Mechanism of wetting alteration by crude oils. SPE J. 3, 54 (1998)

26. Ju, B., Fan, T., Li, Z.: Improving water injectivity and enhancing oil recovery by wettability control using nanopowders. J. Pet. Sci. Eng. 86-87, 206-216 (2012)

27. Kondiparty, K., Nikolov, A., Wason, D., Liu, K.: Dynamic spreading of nanoparticles on solids part I. Langmuir 28(41), 14618-141623 (2012)

28. Kondiparty, K., Nikolov, A.D., Wasan, D., Liu, K.L.: Dynamic spreading of nanofluid on solids. Part 1: experimental. Langmuir 28, 16274 (2012) 
29. Moustafa, E., Noah, A., Beshay, K., Sultan, L.: Investigating the effects of various nanomaterials on the wettability of sandstone reservoir. World J. Eng. Technol. 3, 116-126 (2015)

30. Hendraningrat, L., Torsaeter, O.: Metal Oxide-Based Nanoparticles: Revealing Their Possibility to Enhance the Oil Recovery at Different Wettability Systems. Springer, Berlin (2014)

31. Karimi, B., Gholinejad, M., Khorasani, M.: Highly efficient three-component coupling reaction catalysed gold nanoparticles supported on periodic mesoporous organosilica with ionic liquid framework. J. Chem. Comm. Iss. 7, 8961 (2012)

32. Nwidee, L.N., Al-Anssari, S., Barifcani, A., Sarmadivaleh, M., Lebedev, M., Iglauer, S.: Nanoparticles wetting behaviour of fractured limestone formation. J. Pet. Sci. Eng. 149, 788-798 (2017)

33. Ju, B., Fan, T.: Experimental study and mathematical model of nanoparticles transport in porous media. Powder Tech. 192(2), 195-202 (2009)

34. Li, S., Torsaeter, O.: Experimental investigation of the influence of nanoparticles adsorption and transport on wettability alteration for oil wet berea sandstone. In: SPE-172539-MS, presented at the SPE middle east conference, Manama, Bahrain, 8-11 March (2015)

35. Wan Sulaiman, W., Adala, A., Radzuan, J., Ismail, I., Ismail, R., Hamid, M., Kamaruddin, J., Zakaria, Z., Johari, A., Hassim, H., Abdullah, T., Kidam, K.: Effects of salinity on nanosilica application in altering limestone rock wettability for enhanced oil recovery. Adv. Mater. Res. 1125, 200-204 (2015)

36. Nazari, R., Bahramian, A., Fakhroueian, Z., Karimi, A., Arya, S.: Comparative study of using nanoparticle for enhanced oil recovery: wettability alteration of carbonate rocks. Energy Fuels 29(4), 2111-2119 (2015)

37. Maghzi, A., Mohammadi, S., Ghazanfari, M., Kharrat, R., Masihi, M.: Monitoring wettability alteration by silica nanoparticles during water flooding of heavy oils in five-spot system: a pore-level investigation. Exp. Thermal Fluid Sci. 40, 168-176 (2012)

38. Dai, C., Wang, X., Li, Y., Lv, W., Zou, C., Gao, M., Zhao, M.: Spontaneous inhibition investigation of self dispersing nano fluid for enhanced oil recovery in low permeability cores. Energy Fuels 31(3), 2663-2668 (2017)

39. Roustaei, A., Saffarzadeh, S., Mohammadi, M.: An evaluation of modified silica nanoparticles efficiency in enhancing oil recovery of light and intermediate oil reservoirs. Egypt. J. Pet. 22(3), 427-433 (2013)

40. Huibers, B.M., Pales, R., Bai, L., Li, C., Mu, M., Ladner, D., Daigle, H., Darnault, C.: Wettability alteration of sandstone by silica nanoparticles dispersion in light and heavy oil. J. Nanopart. Res. 19, 323 (2017)

41. Taborda, E., Alvarado, V., Franco, C., Cortes, F.: Rheological alteration in the heavy crude oil fluid structure upon addition of nanoparticles. Fuel 189(1), 322-333 (2017)

42. Wei, Y., Babadagli, T.: Selection of new generation chemicals as steam additive for cost effective heavy oil recovery application. Paper SPE-184975-MS, presented at the SPE Canada Heavy Oil Technical conference, held in Calgary, Alberta, Canada, 15-16 February (2017)

43. Wang, Y., Xu, H., Yu, W., Bai, B., Song, X., Zhang, J.: Surfactant induced reservoir wettability alteration: recent theoretical and experimental advances in enhanced oil recovery. Pet. Sci. 8(4), 463-476 (2011)

44. Joonaki, E., Ghanaantian, S.: Application of nanofluid for enhanced oil recovery application: effect on interfacial tension and core flooding process. Pet. Sci. Technol. 32(21), 2599-2607 (2014)

45. Al-Anssari, S., Barifcani, A., Wang, M., Maxim, M., Iglauer, S.: Wettability alteration of oil-wet carbonate by silica nanofluid. J. Colloid Interface Sci. 461, 435-442 (2016)

46. Peng, B., Zhang, L., Luo, J., Wang, P., Ding, P., Zeng, M., Cheng, $Z$.: A review of nanomaterials for nanofluid enhanced oil recovery. RSC Adv. 7, 32246 (2017)
47. Cheraghian, G., Hendraningrat, L.: A review on applications of nanoparticles in the enhanced oil recovery part a: effect of nanoparticles on interfacial intension. Int. Nano Lett. 6(2), 129-138 (2016)

48. Suleimanov, B.A., Ismailov, F.S., Veliyev, E.F.: Nanofluid for enhanced oil recovery. J. Pet. Sci. Eng. 78(2), 431-437 (2011)

49. Harikrishnan, A.R., Dhar, P., Agnihotri, P., Gedupudi, S., Das, S.: Effects of interplay of nanoparticles, surfactants and base fluid on the surface tension of nanocolloids. Eur. Phys. J. E 40, 53 (2017)

50. Ayatollahi, S.: Nanoparticle assisted EOR techniques: new solution to old challenges. Paper SPE-157094. Presented at the SPE international oil field nanotechnology conference held in Noordwyk, The Netherlands, 12-14 June (2012)

51. Maestro, A., Guzman, E., Santini, E., Ravera, F., Liggieri, L., Ortega, F., Rubio, R.: Wettability of silica nanoparticles-surfactant nanocomposite interfacial layers. Soft Mater. 8, 837-843 (2012)

52. Jung, J., Yoo, J.: Thermal conductivity enhancement of nanofluid in conjunction with electrical double layer (EDL). Int. J. Heat Mass Transf. 52, 525-528 (2009)

53. Ohshima, H., Furusawa, K.: Electrical Phenomena at Interfaces: Fundamental, Measurement, and Applications, 2nd edn. Marcel Dekker Inc., New York (1998)

54. Tan, S., Chee, S., Lin, G., Mirasaidov, U.: Direct observation of interactions between nanoparticles and nanoparticles selfassembly in solution. Acc. Chem. Res. 50, 1303-1312 (2017)

55. Thormann, E.: Surface forces between rough and topographically structured interfaces. Curr. Opin. Colloid Interface Sci. 27, 18-24 (2017)

56. Hendraningrat, L., Li, S., Torsaeter, O.: A core flood investigation of nanofluid enhanced oil recovery. J. Pet. Sci. Eng. 111, 128-138 (2013)

57. Baez, J., Ruiz, M., Faria, J., Harwell, J., Shiau, B., Resasco, D.: SPE-Paper 154052-MS. In: Society of Petroleum Engineers (2012)

58. Ragab, A.M., Hannora, A.E.: An experimental investigation of silica nanoparticles for enhanced oil recovery application. In: Paper SPE-175829-MS, presented at the SPE North Africa Technical Conference and Exhibition held in Cairo, Egypt, 14-16 September (2015)

59. Kim, D., Krishnamoorti, R.: Interfacial activity of poly (oligo (ethylene oxide) monomethyl ether methacrylate) grafted silica nanoparticles. Ind. Eng. Chem. Res. 54(14), 3648-3656 (2015)

60. Abbas, A.H., Wan Sulaiman, W.R., Jafaar, M.Z., Agi, A.A.: Micelle formation of aerosol-OT surfactants in sea water salinity. Arab. J. Sci. Eng. 43, 1-5 (2017)

61. Ahmadi, M., Habibi, A., Pourafshry, P., Ayatollahi, S.: Zeta Potential Investigation and Mathematical Modelling of Nanoparticles Deposited on the Rock Surface to Reduce Fines Migration, Paper SPE-142633, presented at the SPE Middle East Oil and Gas Show and Conference held in Manama, Bahrain, 6-9 March (2011)

62. Godinez, I.G., Darnault, C.: Aggregation and transport of nano$\mathrm{TiO}_{2}$ in saturated porous media: effect of $\mathrm{pH}$, surfactants and flow velocity. Water Res. 45(2), 839-851 (2011)

63. Sheng, J.: Status of surfactant EOR technology. Petroleum 1, 07-105 (2015)

64. Ranka, M., Brown, P., Hatton, T.: Responsive stability of nanoparticles for extreme salinity and high-temperature reservoir. ACS Appl. Appl. Mater. Interface 7(35), 19651-19658 (2015)

65. Bayat, A., Junin, R., Sansuri, A., Piroozian, A., Hokmabadi, M.: Impact of metal oxide nanoparticles on enhanced oil recovery from limestone media at several temperature. Energy Fuel 28(10), 6255-6266 (2014)

66. Zargartalebi, M., Kharrat, R., Barati, M.: Enhancement of surfactant flooding performance by the use of silica nanoparticles. Fuel 143, 2-27 (2015) 
67. Esmaeilzadeh, P., Hosseinpour, N., Bahramian, A., Fakhroueian, Z., Arya, S.: Effect of $\mathrm{ZrO}_{2}$ nanoparticles on the interfacial behaviour of surfactant solutions at air-water and $n$-heptanewater interface. Fluid Phase Equilib. 361, 289-295 (2014)

68. Mittal, G., Dhand, V., Rhee, K., Park, S., Lee, W.: A review on carbon nano tubes and graphene as fillers in reinforced polymer nanocomposites. J. Ind. Eng. Chem. 21, 11-25 (2015)

69. Amani, A., York, P., Chrystyn, H., Clark, B., Do, D.: Determination of factors controlling the particle size in nanoemulsion using artificial neural networks. Eur. J. Pharm. Sci. 35, 42-51 (2008)

70. Alias, N., Ghazali, A., Tengku Mohd, A., Idris, A., Yahyah, E., Yusof, N.: Nanoemulsion applications in enhanced oil recovery and wellbore cleaning: an overview. Appl. Mech. Mater. 754755, 1161-1168 (2015)

71. Agi, A., Junin, R., Gbadamosi, A.O.: Tailoring of nanoparticles for chemical enhanced oil recovery: a review. Int. J. Nanomanuf. (2018) (Article in Press)

72. Gbadamosi, A.O., Junin R., Manan, M.A., Yekeen, N., Agi, A., Oseh, J.O.: Recent advances and prospects in polymeric nanofluids application for enhanced oil recovery. J. Ind. Eng. Chem. (2018). https://doi.org/10.1016/j.jiec.2018.05.020

73. Binks, B.P., Lumpson, S.O.: Influence of particle wettability on the type and stability of surfactant free emulsion. Langmuir 16, 8622-8631 (2000)

74. Pei, H., Zhang, G., Ge, J., Jin, I., Ma, C.: Potential of alkaline flooding to enhance heavy oil recovery through water-in oil emulsion. Fuel 104, 272-278 (2013)

75. Romero, I., Zirrit, J., Mario, A., Rojas, F., Mogollon, J., Paz.,E.: Plugging of high permeability-fractured zone using emulsions, In: SPE 35, 461 presented at the SPE/DOE improved oil recovery symposium, Tulsa, Oklahoma, USA, 13-17 April (1996)

76. Zhang, T., Robert, M.R., Bryant, S.I., Huh, C.: Foam and emulsions stabilized with nanoparticles for potential conformance control applications. In: Paper SPE121744, presented at the spe international symposium on oilfield chemistry, the Woodlands, Texas, USA, 20-22 April (2009)

77. Villamizar, L., Lohateeraparp, P., Harwell, J., Resasco, D., Shiau, B.: Interfacially active SWNT/silica nanohybrid used in enhanced oil recovery. In: Paper SPE-129901-MS, presented at the SPE improved oil recovery symposium, Tulsa, Oklahoma, USA, 26-28 April (2010)

78. Pei, L., Zhao, Q., Chen, C., Liang, J., Chen, J.: Phosphorus nanoparticles encapsulated in graphene scrolls as a high anode for sodium-ion batteries. Chem. Electr. Chem. 2(1), 1652-1655 (2015)

79. Griffith, Ahmad, Y., Daigle, H., Huh, C.: Nanoparticles stabilized natural gas liquid-in-water emulsion for residual oil recovery. In: SPE-179640-MS, presented at the SPE improved oil recovery conference, Tulsa, Oklahoma, USA 11-13 April (2016)

80. Kim, I., Worthen, A., Lotfollahi, M., Johnston, K., DiCarlo, D., Huh, C.: Nanoparticle-stabilized emulsion for improved mobility control for adverse mobility water flooding. 19th European symposium on improved oil recovery (2017)

81. McClements, D.J., Jafari, S.M.: Improving emulsion formation, stability and performance using mixed emulsifiers: a review. Adv. Colloids Interface Sci. 251, 55-79 (2018)

82. Bayat, A.E., Rajaei, K., Radzuan, J.: Assessing the effect of nanoparticles type and concentration on the stability of $\mathrm{CO}_{2}$ foams and the performance in enhanced oil recovery. Colloid Surf. A Physiochem. Eng. Aspect. 115, 222-231 (2016)

83. Yekeen, N., Idris, K., Manan, M., Samin, A.: Experimental study of the influence of silica nanoparticles on bulk foam of SDSfoam in the presence of oil. J. Dispers. Sci. Technol. 38, 3 (2017)

84. Espinoza, C., Caldelas, F., Johnston, K., Bryant, K., Huh, C.: Paper SPE-29925-MS, presented at SPE improved oil symposium (2010)
85. Yekeen, N., Manan, M., Idris, K., Samin, A., Risal, R.: Experimental investigation of minimization in surfactant adsorption and improvement in surfactant-foam stability in the presence of silicon dioxide and aluminium dioxide nanoparticles. J. Petrol. Sci. Eng. 159, 115-134 (2017)

86. Yekeen, N., Manan, M., Idris, K., Samin, A., Risal, R.: Mechanistic study of nanoparticles-surfactant foam flow in etched glass micromodels. J. Dispers. Sci. Technol. 39, 1532-2351 (2017)

87. Yekeen, M., Idris, K., Manan, M., Samin, A., Risal, R., Kun, $\mathrm{X}$.: Bulk and bubble-scale experimental studies of the influence of nanoparticles on foam stability. Chin. J. Chem. Eng. 25(3), 347-357 (2017)

88. Aminzadeh, B., Chung, D.H., Zhang, S., Bryant, S.L., Huh, C., DiCarlo, D.: Influence of surface-treated nanoparticles on the displacement pattern during $\mathrm{CO}_{2}$ injection. In: Paper SPE0166302-MS, presented at the SPE annual technical conference and exhibition held in New Orleans, Louisiana, USA, 30 September-2 October (2013)

89. Yu, J., An, C., Mo, D., Lee, R.: Study of adsorption and transportation behaviour of nanoparticles in different porous media. In: Paper SPE-153337-MS, presented at the eighteenth SPE improved oil recovery symposium, Tulsa, Oklahoma, USA, 14-18 April (2012)

90. Singh, R., Mohanty, K.K.: Foam stabilized in-situ surfaceactivated nanoparticle in bulk and porous media. SPE J. 21(01), 121-130 (2015)

91. Nguyen, P., Fadaei, H., Sinto, D.: Nanoparticle stabilized $\mathrm{CO}_{2}$ in water foam for mobility control in enhanced oil recovery via microfluidic method. In: Paper SPE-170167-MS, presented at the SPE heavy oil conference, Calgary, Alberta, Canada, 10-12 June (2014)

92. Mo, D., Jia, B., Yu, J., Lui, N., Lee, R.: Study of nanoparticle-stabilized $\mathrm{CO}_{2}$ foam for oil recovery at different pressure, temperature and rock sample samples. In: SPE-169110-MS, presented at the SPE improved oil recovery symposium, Tulsa, Oklahoma, USA, 12-16 April (2014)

93. Schrick, B., Hydutsky, B.W., Blough, J.L., Mallouk, T.: Delivery vehicles for zerovalent metal nanoparticles in soil and groundwater. Chem. Mater. 16, 2187-2193 (2004)

94. Zhan, J., Zheng, T., Piringer, G., Day, C., McPherson, G., Lu, Y., Papadopoulos, K., John, V.: Transport characteristics of nanoscale functional zerovalent iron/silica composite for in situ remediation of trichloroethylene. Environ. Sci. Technol. 42(23), 8871-8876 (2008)

95. Li., S., Hendraningrat, L., Torsaeter, O.: Improved oil recovery by hydrophilic silica nanoparticles suspension: 2-phase flow experimental studies. In: Paper IPTC-16707, presented at the international petroleum technology conference, Beijing, China, 25-28 March (2013)

96. Esmaeilzadeh, P., Bahramian, A., Fakhroueian, Z.: Adsorption of anionic, cationic and non-ionic surfactants on carbonate rock in the presence of $\mathrm{ZrO}_{2}$ nanoparticles. Phys. Proced. 22, 63-67 (2011)

97. Bayat, A.E., Radzuan, J., Rahmat, M., Mehrdad, H., Shahaboddin, S.: Influence of clay particles on $\mathrm{Al}_{2} \mathrm{O}_{3}$ and $\mathrm{TiO}_{2}$ nanoparticles transport and retention through limestone porous media: measurements and mechanisms. J. Nanopart. Res. 17, 219 (2015)

98. Shamsi, M., Thompson, N.: Treatment of organic compounds by activated persulfate using nanoscale zerovalent iron. Ind. Eng. Chem. Res. 52, 13564-13571 (2013)

99. Yan, L., Xu, X., Deng, C., Yang, P., Zhang, X.: Immobilization of trypsin on superparamagnetic nanoparticles for rapid and effective prototeolysis. J. Proteome Res. 6(9), 3849-3855 (2007)

100. Kim, H., Phenrat, T., Tilton, R., Lowry, G.: Effect of kaolinite, silica fines and ph on transportation of polymer-modified zero 
valent iron nano-particles in heterogenous porous media. J. Colloid Surf. 370(1), 1-10 (2012)

101. Zabala, R., Mora, E., Cespedes, C., Guarin, L., Acuna, H., Botero, O., Patino, J., Cortes, F.: Application and evaluation of nanofluid containing nanoparticles for asphaltenes inhibition in wells CPSXL. In: Paper OTC-24310, presented at the offshore technology conference, Rio de Janeiro, Brazil, 29-31 October (2013)

102. Hendraningrat, L., Li, S., Suwarno, S., Torsaeter, O.: A glass micromodel experimental study of hydrophilic nanoparticle retention for EOR project. In: Paper SPE 159161, presented at the SPE Russian Oil and Gas Exploration and Production Technical conference and exhibition, Moscow, Russia, 16-18 October (2012)

103. He, F., Zhao, D., Liu, J., Roberts, C.: Stabilization of Fe-Pd Nanoparticles with sodium carboxymethyl cellulose for enhanced transport and dichlorination of soil and groundwater. Ind. Eng. Chem. Res. 46, 29-43 (2007)

104. Chen, H., Ding, Y., Tan, C.: Rheological behaviour of nanofluids. New J. Phys. 9, 367 (2007)

105. Richmond, W., Jones, R., Fawell, P.: The relationship between particle aggregation and rheology in mixed silica-titanium suspension. Chem. Eng. J. 71, 67-75 (1998)

106. Chen, H., Yang, W., He, Y., Ding, Y., Zhang, L., Tan, C., Lapkin, A., Bavykin, D.: Heat transfer and flow behaviour of aqueous suspension of titanate nanotubes (nanofluids). Powder Technol. 183, 63-72 (2008)

107. Alphonse, P., Bleta, R., Soules, R.: Effect of PEG on rheological on stability of nanocrystalline titania hydrosold. J Colloid Interfernce Sci. 337, 81-87 (2009)

108. Penkavava, V., Tihon, J., Wein, O.: Stability and rheology of dilute $\mathrm{TiO}_{2}$-water nanofluid. Nano Scale Res. Lett. 6, 273 (2011)

109. Tseng, W., Wu, C.: Aggregation, rheology and electrophoretic packing structure of aqueous $\mathrm{Al}_{2} \mathrm{O}_{3}$ nanoparticle suspension. Acta Mater. 50, 3757-3766 (2002)

110. Tseng, W., Wu, C.: Sedimentation, rheology and particle packing structure of aqueous $\mathrm{Al}_{2} \mathrm{O}_{3}$ suspensions. Ceram. Int. 29, 821-828 (2003)

111. Prasher, R., Song, D., Wang, J., Phelan, P.: Measurement of nanofluid viscosity and its implication for thermal application. Appl. Phys. Lett. 89, 133108 (2006)

112. Anoop, K., Kabelec, S., Sundararajan, T., Das, S.: Rheology and flow characteristics of nanofluids: influence of electro-viscous effect and particle agglomeration. J. Appl. Phys. 10, 034909 (2009)

113. Tseng, W., Chen, C.: Effect of polymeric dispersant on rheological behaviour of nickel-terpineol suspensions. Mater. Sci. Eng. A 347, 145-153 (2003)

114. Tseng, W., Chen, C.: Dispersion and rheology of nickel nanoparticle ink. J. Mater. Sci. 41(4), 1213-1219 (2006)

115. Tamij, E., Guenther, B.: Rheological and colloidal structure of silver nanoparticles dispersed dispersed in diethylene glycol. Powder Tech. 197, 49-53 (2010)

116. Abdelhalim, M., Mady, M., Ghannam, M.: Rheological and dielectric properties of different gold nanoparticles sizes. Lipid Health Dis. 10, 208 (2011)

117. Duan, F., Wong, T.F., Crivoi, A.: Dynamics viscosity measurement in non-Newtonian graphite nanofluids. Nanoscale Res. Lett. 7, 360 (2012)

118. Moghaddam, M., Goharshadi, E., Entezari, M., Nancarrow, P.: Preparation, characterisation and rheological properties of graphene-glycerol nanofluids. Chem. Eng. J. 231, 365-372 (2013)

119. Hong, R., Pan, T., Han, Y., Li, H., Ding, J., Han, S.: Magnetic field synthesis of $\mathrm{Fe}_{3} \mathrm{O}_{4}$ nanoparticles used as a precursor of ferrofluids. J. Magn. Mater. 310, 37-47 (2007)
120. Phuoc, T., Massoudi, M.: Experimental observations of the effects of shear rates and particle concentration on the viscosity of $\mathrm{Fe}_{2} \mathrm{O}_{3}$-deionized water nanofluids. Int. J. Therm. Sci. 48(1294), 301 (2009)

121. Moattar, M., Cegincara, R.: Stability, rheology, magnetorheological and volumetric characterisation of polymer based magnetic nanofluid. Colloid Polym. Sci. 29, 1977-1987 (2013)

122. Resiga, D., Socoliuc, V., Boros, T., Borbath, T., Marinica, O., Han, A., Vekas, L.: The influence of particle clustering on the rheological properties of highly concentrated magnetic nanofluids. J. Colloids Interfaces Sci. 373, 110-115 (2012)

123. Yang, Y., Grulke, E., Zhang, Z., Wu, G.: Thermal and rheological properties of carbon nanotube in oil dispersiona. J. Appl. Phys. 99, 1-8 (2006)

124. Phuoc, T., Massoudi, M., Chen, R.: Viscosity and thermal conductivity of nanofluid containing multi-walled carbon nanotube stabilized by chitosan. Int. J. Therm. Sci. 50, 12-18 (2011)

125. Yang, Y., Grulke, E., Zhang, Z., Wu, G.: Temperature effect on the rheological properties of carbon nanotube-in-oil dispersion. Colloid Surf. A. 298, 216-224 (2007)

126. Tseng, W., Li, C.: Effects of dispersant on the rheological behaviour of $\mathrm{BaTio}_{3}$ powder in ethanol-isopropanol mixture. Mater. Chem. Phys. 80, 232-238 (2003)

127. Tseng, W., Li, S.: Rheology of colloids $\mathrm{BaTio}_{3}$ suspension with ammonium polyacrylate as a dispersant. Mater. Sci. Eng. A 333, 314-319 (2002)

128. Tseng, W., Tzeng, F.: Effect of ammonium polyacrylate on dispersion and rheology of aqueous ITO nanoparticles colloids. Colloid Surf. A 276, 34-39 (2006)

129. Litchfield, D., Baird, D.: The rheological high aspect ratio nanoparticle filled liquids. Rheol. Rev. 2006, 1-60 (2006)

130. Einstein, A.: On the theory of brownian motion. Ann. Phys. (Leipz) 19, 371-381 (1906)

131. Baker, F.: The viscosity of cellulose nitrate solutions. J. Chem. Soc. Trans. 103, 1653-1675 (1913)

132. Krieger, I., Dougherty, T.: A mechanism for non-Newtonian flow in suspension of non-rigid spheres. Trans. Soc. Rheol. 3, 137-152 (1959)

133. Batchelor, G.: The stress generated in a non-dilute suspension of elongated particles by pure straining motion. J. Fluid Mech. 46, 813-829 (1971)

134. Quemada, D.: Rheology of concentrated dispersed system and minimum energy dissipation principle: I. Viscosity-concentration relationship. Rheol. Acta 16, 82-94 (1977)

135. Tsai, S., Botts, D., Plouff, J.: Effects of particles properties on the rheology of concentrated non-colloidal suspensions. J. Rheol. 36, 1291-1305 (1992)

136. Cheraghian, G., Khalilinezhad, S.: Effect of nanoclay on heavy oil recovery during polymer flooding. Pet. Sci. Technol. 33, 999-1007 (2015)

137. Cheraghian, G.: Effect of nano titanium dioxide on heavy oil recovery during polymer flooding. Pet. Pol. Tech. 34(7), 633-641 (2016)

138. Charaghian, G.: Application of nano-fumed silica in heavy oil recovery. Pet. Sci. Tech. 34(1), 12-18 (2016)

139. Ma, Y., Bhattacharya, A., Kuksenok, O., Perchak, D., Balazs, A.: Modelling the transport of nanoparticle-filled binary fluid through micropores. Langmuir 28, 11410-11421 (2012)

140. Cleary, P., Ha, J., Sawley, M.: Modelling industrial fluid flow application using SPH. In: Muhlhaus, H.B. (ed.) Bifurcation and Localization Theory in Geomechanics. Swets and Zeitlinger, Lisse (2001)

141. El-Almin, M., Saad, A., Sun, S., Salama, A.: Numerical simulation of magnetic nanoparticles injection into two-phase flow in a porous media. Procedia Comput. Sci. 108, 2260-2264 (2017) 
142. El-Amin, M., Brahimi, T.: Numerical modelling of magnetic nanoparticles transport in a two-phase flow in porous media. Paper SPE-185973-MS, presented at the SPE reservoir characterization and simulation conference and exhibition, held in Abu Dhabi, UAE, 8-10 May (2017)

143. Zou, H., Wu, S., Shen, J.: Polymer/silica nanocomposites: preparation, characterisation, properties and applications. Chem. Rev. 108(9), 3893-3957 (2008)

144. Jana, S., Jain, S.: Dispersion of nanofillers in high performance polymers using reactive solvent as processing aids. Polymer 42(16), 6897-6905 (2001)

145. Guo, S., Dong, S., Wang, E.: Gold/platinum nanoparticles supported on multi-walled carbon nanotube/silica coaxial nanocables: preparation and application as electrocatalysts for oxygen reduction. J. Phys. Chem. C 112, 2389-2393 (2008)

146. Sabzi, M., Mirabedini, M., Zohuriaan-Mehr, J., Atai, M.: Surface modification of $\mathrm{TiO}_{2}$ nanoparticles with silane coupling agent and investigation of its effect on the properties of polyurethane composite coating. Progress Org. Coat. 65(2), 222-228 (2009)

147. Iijima, M., Kabayakawa, M., Kamiya, H.: Tuning the stability of $\mathrm{TiO}_{2}$ nanoparticles in various solvent by mixed silane alkoxides. J. Colloid Interface Sci. 337(1), 61-65 (2009)

148. Ukaji, E., Furusawa, T., Sato, M., Suzuki, N.: Effect of surface modification with silane coupling agent on suppressing the photo-catalytic activity of fine $\mathrm{TiO}_{2}$ particles as inorganic UV filter. Appl. Surf. Sci. 254(2), 536-569 (2007)

149. Wu, J., Yang, S., Gao, S., Hu, A., Liu, J., Fan, L.: Preparation, morphology and properties of nano-sized $\mathrm{Al}_{2} \mathrm{O}_{3}$ /polyimide hybrid films. Eur. Polym. J. 41(1), 73-81 (2005)

150. Mahdavian, A., Ashjari, M., Makoo, A.: Preparation of poly (styrene-methyl methacrylate)/ $/ \mathrm{SiO}_{2}$ composite nanoparticles via emulsion polymerization. An investigation into the compatibilization. Eur. Polym. J. 43(2), 336-344 (2007)

151. Reculusa, S., Ponect-Legrand, C., Ravaine, S., Mingotaud, C., Duguet, E., Bourgeat-Lami, E.: Syntheses of raspberrylike silica/polystyrene materials. Chem. Mater. 14(5), 2354-2359 (2002)

152. Lai, Y., Kuo, M., Huang, J., Chen, J.: On the PEEK reinforced surface-modified nano-silica. Mater. Sci. Eng. A 458(1-2), 158169 (2007)

153. Tang, J., Lin, G., Yang, H., Jiang, G., Chen-Yang, Y.: Polyimidesilica nanocomposites exhibiting low thermal expansion coefficient and water adsorption from surface-modified silica. J. Appl. Polym. Sci. 104(6), 4096-4105 (2007)

154. Behzadi, A., Mohammadi, A.: Environmentally responsive surface-modified silica nanoparticles for enhanced oil recovery. J. Nanopart. Res. 18, 266 (2016)

155. Yang, P., Hu, J., Zhou, X., Xia, J., Shi, J., He, J.: Synthesis of graphene nanosheets modified with the $\mathrm{Fe}_{3} \mathrm{O}_{4} @$ phenol formaldehyde resin or PFR nanoparticles for their bio-image and thermal treatment. J. Appl. Polym. Sci. 134, 26 (2017)

156. Afzali-Tabar, M., Alaei, M., Bazmi, M., Khojasteh, R., Koolivand-Salooki, M., Motiee, F., Rashidi, A.: Facial and economical preparation method of nanoporous graphene/silica nanohybrid and evaluation of its pickering emulsion properties for chemical enhanced oil recovery (C-EOR). Fuel 206, 453-466 (2017)

157. Bhatia, S.: Nanoparticles types, classification, characterization, fabrication method and drug delivery applications. Nat. Polym. Drug Deliv. Syst. (2016). https://doi.org/10.1007/978-3-31941129-3_2

158. Roque, L., Castro, P., Molpeceres, J., Viana, A., Roberto, A., Reis, C., Rijo, C., Tho, I., Sarmento, B., Reis, C.: Bioadhesive polymeric nanoparticles as strategy to improve the treatment of yeast infections in oral cavity: in-vitro and ex-vivo studies. Eur. Polym. J. 104, 19-31 (2018)
159. Uskokovic, V.: Dynamic light scattering based microelectrophoresis: main prospects and limitations. J. Dispers. Sci. Technol. 33(12), 1762-1786 (2012)

160. Hoo, C., Starostin, N., West, P., Mecartney, M.: A comparison of atomic force microscopy (AFM) and dynamic light scattering (DLS) methods to characterize nanoparticles size distributions. J. Nanopart. Res. 10, 89-96 (2008)

161. Saveyn, H., Baets, B., Thas, O., Hole, P., Smith, J., Meeren, P.: Accurate particles size distribution determination by nanoparticles tracking analysis based on 2-D dynamics simulation. J. Colloids Interface Sci. 352(2), 593-600 (2010)

162. Pangi, Z., Beletsi, A., Evangelatos, K.: PEG-ylated nanoparticles for biological and pharmaceutical application. Adv. Drug Deliv. Rev. 24, 403-419 (2013)

163. Cheraghian, G., Khalili, N., Kamari, M., Hemmati, M., Masihi, M., Bazgir, S.: Absorption polymer on reservoir rock and the role of nanoparticles, clay, and $\mathrm{SiO}_{2}$. Int. Nano. Lett. 4, 114 (2014)

164. Chengara, A., Nikolov, A., Wasan, D.T., Trokhymchuck, A., Henderson, D.: Spreading nano fluid driven by the structural disjoining pressure gradient. J. Colloid Interface Sci. 280, 192-201 (2004)

165. Wason, D.T., Nikolov, A., Kondiparty, K.: The wetting and spreading of nanofluid on solids on solid: role of the structural disjoining pressure. Curr. Opin. Colloid Interface Sci. 16, 344 349 (2011)

166. Hendraningrat, L., Torsaeter, O.: Unlocking the potential of metal oxide nanoparticles to enhance oil recovery. Paper OTC24696-MS. Presented at the offshore technology conference, held in Kuala Lumpur, Malaysia, 25-28 March (2014)

167. Cheraghian, G.: Application of nano fumed silica in heavy oil recovery. Pet. Sci. Technol. 34, 12 (2015)

168. Cheraghian, G.: Thermal resistance and application of nanoclay on polymer flooding in heavy oil recovery. Pet. Sci. Technol. 33(17-18), 1580-1586 (2015)

169. Manan, M.A., Farad, S., Piroozian, A., Esmail, M.J.: Effect of nanoparticle types on carbon dioxide foam flooding in enhanced oil recovery. Pet. Sci. Technol. 33(12), 1286-1294 (2015)

170. Moradi, B., Pourafshary, P., Farahani, F., Mohammadi, M., Emadi, M.: Application $\mathrm{SiO}_{2}$ nanoparticle to improve the performance of water alternating gas EOR process In: Paper SPE178040 , presented at the SPE oil and gas conference and exhibition, Mumbai, Indian, 24-26 November (2015)

171. El-Diasty, A.: The potential of nanoparticles to improve oil recovery in Bahariya formation, Egypt: an experimental study. In: Paper SPE-174599-MS, presented at the SPE Asia Pacific Enhanced Oil Recovery conference, held in Kuala Lumpur, Malaysia, 11-13 August (2015)

172. Chen, C., Wang, S., Kadhum, M., Harwell, J., Shiau, B.: Using carbonaceous nanoparticles as a surfactant carrier in enhanced oil recovery: a laboratory study. Fuel. 222, 561-568 (2018)

173. Alomair, O.A., Matar, K.M., Alsaeed, Y.H.: Experimental study of enhanced heavy oil recovery in berea sandstone cores by use of nanofluid application. SPE Reserv. Eval. Eng. 18(03), 387399 (2015)

174. Jafarnezhad, M., Giri, S.M., Alizadeh, M.: Impact of $\mathrm{SnO}_{2}$ nanoparticles on enhanced oil recovery from carbonate media. Energy Source Part A Recov. Util. Environ. Eff. 39(1), 121-128 (2017)

175. Azarshin, S., Moghadasi, J., Aboosadi, Z.A.: Surface function of silica nanoparticles to improve the performance of water flooding in oil wet reservoir. Energy Explor. Exploit. 1, 13 (2017)

176. Zallaghi, M., Kharrat, R., Hashemi, A.: Improving the microscopic sweep efficiency of water flooding using silica nanoparticles. J. Pet. Explor. Prod. Technol. 8(1), 259-269 (2018) 
177. Youssif, M.I., El-Maghraby, R.M., Saleh, M.S., Elgibaly, A.: Silica nanofluid flooding for enhanced oil recovery in sandstone rock. Egypt. J. Pet. 27(1), 105-110 (2018)

178. Ohiaki, C.: Nanosandwitches. Chem. Br. 34, 59-62 (1998)

179. Schmidt, D., Shah, D., Giannelis, E.: New advances in polymer/ layered silicate nanocomposite. Curr. Option Solid State Mater. Sci. 6(3), 205-212 (2002)

180. Lau, K., Sankar, J., Hui, D.: Enhancement of the mechanical strength of polymer-based composite using carbon nanotubes. In: Schulz, M., Kelker, A., Sunderason, M. (eds.) Nanoengineeering of Structural, Functional and Smart Materials. Taylor \& Francis, USA (2006)

181. Muller, J., Huaux, F., Liason, D.: Respiratory toxicity of carbon nanotube: how worried should we be? Carbon 44, 1048-1056 (2006)
182. Warheit, D.B.: What is currently known about the health risk related to carbon nanotube exposures? Carbon 44, 1064-1069 (2006)

183. Borm, P.: Particle toxicology: from coal to nanotechnology. Inhal. Toxicol. Med. 61, 727 (2002)

184. Donaldson, K., Stone, V., Tran, C., Kreyling, W., Borm, P.: Nanotoxicology. Occup. Environ. Med. 61, 727 (2004)

Publisher's Note Springer Nature remains neutral with regard to jurisdictional claims in published maps and institutional affiliations. 